\title{
THE HETEROGENEOUS PRICE OF A VOTE: EVIDENCE FROM MULTIPARTY SYSTEMS, 1993- 2017
}

Yasmine Bekkouche, Julia Cagé, and Edgar Dewitte

SCIENCES PO ECONOMICS DISCUSSION PAPER

No. $2020-07$ 


\title{
The Heterogeneous Price of a Vote: Evidence from Multiparty Systems, 1993-2017*
}

\author{
Yasmine Bekkouche ${ }^{\dagger 1}$, Julia Cagé ${ }^{\ddagger 2}$, and Edgard Dewitte ${ }^{\S 3}$ \\ ${ }^{1}$ Université Libre de Bruxelles, ${ }^{2}$ Sciences Po Paris and CEPR, ${ }^{3}$ Sciences Po Paris
}

December 28, 2020

\begin{abstract}
What is the impact of campaign spending on votes? Does it vary across election types, political parties or electoral settings? Estimating these effects requires comprehensive data on spending across candidates, parties and elections, as well as identification strategies that handle the endogenous and strategic nature of campaign spending in multiparty systems. This paper provides novel contributions in both of these areas. We build a new comprehensive dataset of all French legislative and UK general elections over the 1993-2017 period. We propose new empirical specifications, including a new instrument that relies on the fact that candidates are differentially affected by regulation on the source of funding on which they depend the most. We find that an increase in spending per voter consistently improves candidates' vote share, both at British and French elections, and that the effect is heterogeneous depending on candidates' party. In particular, we show that spending by radical and extreme parties has much lower returns than spending by mainstream parties, and that this can be partly explained by the social stigma attached to extreme voting. Our findings help reconcile the conflicting results of the existing literature, and improve our understanding of why campaigns matter.
\end{abstract}

\footnotetext{
*We gratefully acknowledge the many helpful comments and suggestions from Micael Castanheira, Denis Cogneau, Thomas Ferguson, Nicolas Jacquemet, Benjamin Marx, Maria Petrova, Thomas Piketty, Vincent Pons, Joanne Tan, Clémence Tricaud, and Katia Zhuravskaya. We thank Michael Tomz for his precious help with the statistical suite Clarify, and Olivier Godechot for guiding us through the use of the DADS data. We are also grateful to seminar participants at the Berkeley Center for Economics and Politics, Columbia University, New York University, the Paris School of Economics, Sciences Po Paris, Yale University and Uppsala University, and to conference participants at the Junior Workshop on Political Economy (CREST - Ecole Polytechnique - ENSAE), the CEPR Public Economics Annual Symposium 2018, the INET 2017 Conference (Edinburgh) and the NBER Political Economy Meeting (Fall 2017). We thank Julien Bachorz and Patrick Roger for sharing Le Monde data on candidates' political affiliation, and Pierre Letessier for his precious help with the downloading of the Wikipedia data. Francesco Gerotto, Paul Gioia, Elisa Mougin, Ana Muresan, and Sébastien Nerincx provided outstanding research assistance. This research was generously supported by the Institute for New Economic Thinking (grant INO1500035). It is also supported by a public grant overseen by the French National Research Agency (ANR) as part of the "Investissements d'avenir" program (reference: ANR-10-EQPX-17 - Centre d'accès sécurisé aux données - CASD). An online Appendix with additional empirical material is available here All errors remain our own.

${ }^{\dagger}$ ECARES, Université Libre de Bruxelles (yasmine [dot] bekkouche [at] psemail [dot] eu).

${ }^{\ddagger}$ Corresponding author. Sciences Po Paris and CEPR (julia [dot] cage [at] sciencespo [dot] fr).

${ }^{\S}$ Sciences Po Paris (edgard [dot] dewitte [at] sciencespo [dot] fr).
} 


\section{Introduction}

Can money buy an election in a multiparty system? In their seminal work, Grossman and Helpman (1996, 2001) highlighted the different mechanisms through which special interest groups could affect policy in modern democracies. Among them was the ability to increase the likelihood of a candidate being elected by contributing to her campaign spending. This assertion has been the base of numerous regulatory debates, but academic research, though substantial, has yet to reach a consensus as to its validity (Levitt, 1994, Gerber, 1998; Ansolabehere et al., 2003, Kalla and Broockman, 2018).

In addition, the campaign spending literature has been characterized by a strong focus on the United States, which, "in the postwar period, [...] stands alone as the only industrialized country with a consistent two-party system" (Tomz et al. 2002). If the number of parties depends on contingent histories and institutional decisions (Duverger, 1954), evidence suggests that it strongly influences the behaviors of both voters and candidates (Cox, 1997, Adams et al., 2005). Hence, it might also affect the efficiency of campaigns and their expenditures. Likewise, the impact of campaign spending may be heterogeneous across political parties. As such, the study of campaign spending in multiparty systems could not only improve our understanding of where and why campaigns matter, but also shed new light on the characteristics, positioning and perception of political parties themselves - in particular those on which we know relatively little, such as the new radical right (Guriev and Papaioannou, 2020).

This paper investigates the impact of candidates' spending on votes in two large, multiparty democracies: France and the United Kingdom. We build a new, exhaustive dataset on campaign finance at the candidate level for all the French legislative elections since 1993 and the UK general elections since 1997. We adapt models of multiparty analysis to the use of campaign spending, and document a strong positive correlation between campaign spending and votes. Using a new instrumental variable, we provide evidence that this relationship is, at least in part, causal. We then show that it differs significantly across political parties, with the candidates of extreme parties systematically facing the highest "price of a vote". Discussing the mechanisms behind these findings allows us to better understand why money matters, and to make sense of the ambiguous results studies have found using US data.

We start by building an extended version of the Conditional Logit model that allows the use of aggregate data and information from all political parties, through the inclusion of abstention in voters' choice set. Our estimations, which include fixed effects for electoral districts and elections, as well as, in some specifications, for candidates, control for time-varying candidates' observables and districtlevel socio-economic covariates. We consistently obtain a positive, robust and statistically significant correlation between a candidate's spending and her vote count, whether we consider French legislative or UK general elections. The magnitude of this correlation is relatively large: a one percentage-point increase in a candidate share of district spending, i.e. an additional $€ 500$ to $€ 1,000$, is associated with a rise in her vote counts of 0.2 to 0.3 percentage point. 
We then show that these results are robust to instrumenting campaign expenditures. A key issue, the endogeneity of campaign spending has been variously tackled by the literature 1 This paper proposes to use as an instrument a natural experiment that directly impacted candidates' spending: the 1995 ban on political contributions from legal entities in France, which was enforced for the first time at the unanticipated 1997 legislative elections. We exploit the fact that candidates varied significantly on their reliance on such donations, and so orthogonally to the other determinants of their electoral fortunes. To ascertain that last point, we restrict our analysis to candidates within the same party. We find that lower campaign spending due to a drop in legal entity contributions translated into a relatively weaker electoral performance, with magnitudes similar to those obtained with fixed-effects specifications. We confirm these results with a matching estimator and support the validity of our exclusion restriction through a variety of placebo tests.

Next, we build on the models of Katz and King (1999); Honaker et al. (2002); Tomz et al. (2002) to study the party-level heterogeneity of campaigns. Concretely, we estimate a seemingly unrelated system of equations (SUR) of the impact, in each district, of each party spending on every party's vote share. This allows us to separate the effect of each party's spending on its own votes from its effect on the votes for the other parties. Besides, we perform counterfactual estimations to compute, for each party, the marginal increase in spending needed to capture an additional vote: the "price of a vote".

We find that the price of a vote significantly differs across political parties (from $€ 2$ to $€ 93$, depending on the year and the country), and in particular is systematically larger - up to ten times - for extreme parties. In other words, campaign spending seems to be generally less efficient when spent by extreme-parties candidates, and far-right candidates in particular. Strikingly, this last point is true both in France and in the UK, while the Front National and the UK Independence Party significantly differ both in their history and political positioning. We discuss a number of potential explanations, among which a valence disadvantage, a salience effect, and an ideological effect. We also show that far-right campaigns are more efficient in districts where the stigma attached to far-right voting is lower.

Our analysis also allows us to have a comprehensive picture of how voters from a particular party respond to spending by other parties. We find evidence of strong, negative cross-party effects - when party A increases its spending, party B's vote share decreases - suggesting that a significant portion of individuals may switch their votes across parties in response to changes in campaign spending. While in the UK this happens across all major parties, in France it seems to be mostly concentrated among parties from the same side of the left-right political spectrum. Interestingly, we also find that most of the switching related to UKIP spending occurs with the Labour Party, echoing studies that find that the new radical-right tends to focus on left-leaning, working-class voters (see e.g. Dal Bo et al. 2019;

1The main focus has been to remove the unobserved candidates' heterogeneity that would affect their decision to run or their fundraising abilities: Levitt (1994) uses same-races repetition in U.S. Congressional elections, while Gerber (1998) instruments spending with variables affecting fundraising abilities, such as wealth levels. In the face of conflicting results, later research has resorted to survey data (Jacobson 2006) or field experiments (see Gerber, 2004, for a review). Recent papers in the campaigning literature use fine grain geographical data to exploit quasi-random variations in exposure to campaign advertising (Spenkuch and Toniatti 2018, Larcinese and Miner 2018). 
Piketty, 2018).

Finally, we leverage the diverse characteristics of our electoral settings and districts to shed light on the mechanisms behind our findings. We provide evidence of both mobilization and persuasion effects. In particular, we find that campaign spending is more efficient in places where citizens are on average more educated and have a higher occupational status, and is positively correlated with turnout. These effects seem to be driven by information provided to voters, rather than by the dissuasion of other candidates: an exogenous rise in the incumbent's spending (measured through our instrumental variable strategy) indeed increases the number of her challengers and their spending. We also show that campaign spending displays decreasing marginal returns, which explains in part the difference in magnitude between our estimates for French legislative and UK general elections. In fact, this finding helps rationalize the minimal effects studies have found in the US (Levitt, 1994) but also in Israel (Ben-Bassat et al. 2015), two countries where campaign spending is very high in relative terms.

As such, this paper contributes to the literature that helps explain political finance patterns through the lens of countries other than the US (see Scarrow, 2007, for a review), for which there is comparatively much less information. At least two dimensions make the US results hard to extrapolate to other contexts. First, as we already highlighted, the US is one of the only Western democracies with only two effective parties while studies have shown the number of parties mattered for campaigning decisions (see e.g. Gandhi et al. 2015). Second, it has no limit on how much candidates can spend in elections - contrary to France and the UK, but also Belgium, Brazil, Canada, Chile, Italy, New Zealand, and South Korea, among others (Gunlicks, 1993; Nassmacher, 2009, Speck. 2013, Cagé, 2018) -, while spending limit has also been shown to determine the dynamics of both fundraising and spending (Avis et al., 2017).

A few studies investigate the effect of campaign expenditures outside the US (Palda and Palda, 1998; Foucault and François, 2005; Benoit and Marsh, 2008, Da Silveira and De Mello, 2011;, Johnston and Pattie, 2014, Ben-Bassat et al., 2015; François et al., 2016, Carvalho, 2020). However, they either reproduce the challenger-incumbent dichotomy, or at least abstract from a systematic investigation of the political party heterogeneity in the efficiency of spending. One notable exception is Rekkas (2007), who develops a model à la Berry et al. (1995) to study own- and cross-party spending elasticities at the 1997 Canadian elections 3 By bringing this question to a new scale -25 years, 12 elections, 2 countries - and to new issues - such as the rise of populist parties -, our analysis aims to establish a more comprehensive view on the dynamics of campaigns - and of campaign spending in particular.

The remainder of the paper is organized as follows. Section 2 provides background on campaign

2This is one of the reasons why the US literature has mainly centered around whether challengers' spending is more effective than that of incumbents: Jacobson (1978, 1980, 1985 1990 2006); Abramowitz (1988); Green and Krasno (1988); Gerber (1998); Erikson and Palfrey (1998).

${ }^{3}$ In the online Appendix Section $G$ we use the same methodology on our data, and discuss its pros and cons. François et al. (2016) use a similar approach to exploit the reforms between French legislative elections of 1993 and 1997. However, contrary to this paper, they do not instrument spending using the 1993 reliance on corporate donations, making causal inference unclear. 
finance laws in France and the UK, introduces the new dataset we built for this study and provides descriptive statistics. In Section 3, we discuss our three different empirical strategies - Conditional logit, Instrumental variables, and Multivariate logistic transformation - and use them to estimate the effect of candidates' expenditures on their own vote shares. In Section 4, we investigate the heterogeneity of the effects of spending depending on the political parties, and study the cross-party effects of campaign expenditures. In Section 5, we discuss the different mechanisms at play and the external validity of our findings. Section 6 concludes.

\section{Campaign finance in France and the UK}

\subsection{Rules and definitions}

\subsubsection{Election expenses and their limits}

France The laws of March 111988 were the first to directly regulate political financing in France 4 They required election candidates to publish and limit their electoral expenses, while introducing an indirect public funding through a partial reimbursement of these expenses. Candidates and parties were allowed to receive private donations, but with a limited maximum amount. A direct public funding of national parties was also established, and further developed by the law of 15 January 1990. The 1990 law also created the "Comission Nationale des Comptes de Campagne et des Financements Politiques" (CNCCFP), which has been checking and approving candidates' campaigns accounts since then. Finally, the law of 19 January 1995 prohibited all donations from legal entities (and in particular from corporations) to candidates and parties: this was an important change as many candidates were relying heavily on donations from legal entities (a fact we exploit in the empirical analysis).

As of today, French law regulates all spending "whose objective is to obtain votes", incurred within a period of 6 months before the first day of the election month. A specific, small subset of these expenses - the so-called “dépenses officielles”, i.e. the printing of leaflets, posters and ballots - are considered essential and fully paid by the State. Candidates have to provide a detailed account, including written evidence, of all other spending and revenues to the CNCCFP within the six months following the election. Importantly, advertising on television and radio is prohibited, and advertising in newspapers and telephone calls is limited, and forbidden during the three months preceding the election.

These electoral expenses are subject to spending limits (the "dépenses officielles" are not included in this limit). Between 1991 and 1995, candidates' spending was capped at a fixed amount, only depending on whether the constituency had fewer or more than 80, 000 inhabitants. Since 1995, the limit is composed of a flat rate $(€ 38,000)$ and an additional amount proportional to the population of the constituency (€0.15 per inhabitant). Both are updated every three years to follow inflation.

\footnotetext{
${ }^{4}$ This section partly draws on Gunlicks (1993) for the 1988-1993 period and on Cagé (2018) for recent years. See online Appendix Section A for more details on each reforms.
} 
United Kingdom In the UK, campaign finance rules for General Elections candidates have been relatively stable over our period of study. The 1983 Representation of the People Act consolidated the rules set up 100 years before by the 1883 Corrupt and Illegal Practice Act, which required all candidates to list their election expenses, and limited the nature and the amounts of these expenses.5 But major reforms occurred for the finances of national parties, which were previously barely regulated. The 2000 Political Parties Elections and Referendums Act (PPERA) in particular set up limits to national campaigns and a (relatively small) direct public funding of the parties, the "Public Development Grant". It also required parties to record the names of their large ( $£ 200$ or more) donors; and created a dedicated administrative body, the Electoral Commission, to centralize and monitor this information.

General election expenses in the UK include all the spending incurred by a candidate for the promotion of her candidacy. Initially, no time period was clearly defined - in order to allow for case-to-case appreciation - but the PPERA 2000 set up a "regulated period", which would start at the official dissolution of Parliament and end on the day of the election. In most cases, this period varied from 3 to 6 weeks - much less than in France, partly because of the unpredictable nature of British elections before the 2011 Fixed Parliament Act 6 Advertising on all broadcasting media is forbidden, but not in newspapers.

Spending limits are calculated with a formula that has remained the same over the years: a fixed amount plus a variable one depending on the number of registered voters in the constituency. Those amounts differ on whether the constituency is a borough (mostly urban) or a county (mostly rural), to account for the larger area of the latter. They are modified regularly to adapt to the changes in both inflation and the electorate: in 2017 , the fixed amount was $£ 8,700$, plus $6 \mathrm{p}$ per registered voter in boroughs, or $8 \mathrm{p}$ per registered voter in counties.

\subsubsection{Funding of campaigns and parties}

France The funding of campaigns in France comes from both private and public sources. An individual may contribute up to $€ 4,600$ to each campaign, and donate an annual maximum of $€ 7,500$ to political parties or groups. Donations to both campaigns and parties are tax deductible. There is also a direct public funding of campaigns: candidates who win more than $5 \%$ of the votes in the first ballot are reimbursed for their personal contributions (i.e. those coming from the candidate's own money or loans she contracted) up to $47.5 \%$ of the spending limit:7

United Kingdom The UK is one of the few countries to have no limit on how much one can give to political parties and candidates, and it also allows corporate donations. The only constraint is for

${ }^{5}$ For more details on the long-term history of British campaign spending, see Cagé and Dewitte (2018).

${ }^{6}$ Note, however, that to account for the fact that campaigns could start before the official dissolution of Parliament when their expiry was coming close, the Political Parties and Elections Act (PPEA) 2009 established that a proportion of the expenses incurred after the 55th month of Parliament by candidates(-to-be) was also campaign expenditures, with their own limits.

${ }^{7}$ Candidates are not refunded if their accounts are not approved by the CNCCFP. 
an individual to be a UK resident, and for a legal entity to be registered in the country. At the same time, there are a few forms of public funding of parties: aside from the Public Development Grant mentioned earlier, which allocates $£ 2$ million every year to national parties based on their parliamentary representation, the Capital Transfer Tax Act 1984 exempted from inheritance tax all donations to parties with at least two seats in the House 8 Nevertheless, these flows of revenues mostly remain in national parties' accounts: in practice, local candidates and parties - on which this study is focused - mostly rely on local fundraising and personal money to finance their campaigns.

\subsection{Data and descriptive statistics}

We create a new, exhaustive dataset on campaign finance and electoral results at the candidate level, for all the French legislative elections since 1993 and the UK general elections since 1997.9 Producing these data is our first contribution. We do it by computing and merging information from several sources, both official and research-based. Our dataset also includes information on electoral districts' socio-demographic information from censuses, and candidates' characteristics from multiple sources. In the online Appendix Sections C.2 and C.3, we describe in detail the different steps we followed to merge the information together, and in particular identify the candidates across sources and from one election to another. In this section, we present each dataset in turn and provide descriptive statistics.

\subsubsection{Data on electoral results}

French legislative elections The French legislative elections select members of the Assemblée Nationale, the lower House, via a two-round system. The 577 constituencies are single-member constituencies. In this article, we focus on the 553 (539 since 2012) constituencies that are in metropolitan France, excluding the French overseas territories. If a candidate obtains an absolute majority in the first round, as well as a minimum of $25 \%$ of all registered voters, then she is elected. If no candidate obtains an absolute majority in the first round, there is a second round where the two most-voted candidates and the candidates who obtained more than $12.5 \%$ of the registered voters can take part. The candidate who obtains the majority of the votes then wins.

The electoral data for French elections come from the Interior ministry, Cagé (2020) and the daily newspaper Le Monde 10

${ }^{8}$ Public funds were in fact allocated to Opposition parties of the Commons since 1974 (and of the House of Lords since 1996) but were technically restricted to the performance of parliamentary duties. Moreover, their amount has always been relatively low.

${ }^{9}$ For France, these are all years for which campaign spending data exist; for the UK, 1997 was chosen because it is the first general election in which UKIP, a special focus of this article, participated. For a longer time series of British campaign spending, see Cagé and Dewitte (2018).

${ }^{10} \mathrm{We}$ had to combine data from all these different sources in particular because, except for the most recent years, the Interior ministry data do not provide the parties of the candidates. 
UK general elections The UK General Elections select Members of Parliament (MPs) of the House of Commons, the lower chamber of the British legislative body. They are held in parliamentary constituencies through a first-past-the-post system, i.e. the candidate with the largest amount of votes in the constituency is elected. The number of constituencies and their boundaries have changed over time, to adapt to the evolution of demography, the latest change being in 2005 . We consider all 569 England and Wales constituencies.

In the UK, electoral results were attached to the Parliamentary Papers reporting election expenses: our 1997 electoral data originate there. For recent years, results are published directly by the Electoral Commission. In total, our data contain information for 40, 609 unique candidates for French legislative elections, and 18, 344 for UK general elections. As shown in the online Appendix Table D.1] the number of candidates per constituency has slightly increased over time, both in France and in the UK.

\subsubsection{Data on campaign revenues and expenditures}

We collect data on campaign resources and expenditures at the highest possible level of detail. For France, it comes from paper data that we digitize and merge: the official reports on election campaign costs and expenditures ( "Publication simplifiée des comptes de campagne") published by the CNCCFP. Online Appendix Figure C.1 provides an example of these data. For the UK, data before the creation of the Electoral Commission was published in paper format as the "Return of expenses of each candidate at the General Election of [date]" in the UK Parliamentary Papers, which we also digitized and encoded. After 2001, the data are published on the Electoral Commission website.

Total spending Table 1 presents summary statistics on candidates' spending $\square$ All figures are in constant 2017 euros. The average spending per candidate at all French legislative elections under scrutiny is equal to $€ 13,878$. This figure hides quite a lot of temporal variation: from 20,397 in 1993 to 12,708 in 200712 Normalized by the number of registered voters, candidates spend on average $€ 0.2$ per voter. Candidates tend to spend less on average at UK general elections: $€ 5,167$, which amounts to $€ 0.07$ per registered voter. This is partly due to stricter spending limits and to campaigns that are on average shorter in time - we will come back to this point.

[Table 1 about here.]

\footnotetext{
${ }^{11}$ Online Appendix Figures E.1 and E.2 plot the distribution of the spending per registered voters for each election.

${ }^{12}$ Note that part of the drop in the number of candidate-elections in 2012 for French legislative elections is due to a change in the reporting requirement rules: since the 2012 election, candidates who obtain less than $1 \%$ of the cast votes do not have to report their spending. However, the increase in average spending between the 2007 and the 2012 legislative elections is not due to this drop in the number of candidates reporting. In the online Appendix Figure E.3 we plot from 1993 to 2017 the campaign resources of only those candidates who obtained more than $1 \%$ of the cast votes. While those candidates tend to have higher revenues on average, the trends are similar (displaying a drop from 1993 to 2007 and then an increase). We also show that our results are robust to dropping the candidates who obtain less than $1 \%$ of the cast votes in the robustness section 3.1 .3
} 
Table 2 displays the same descriptive statistics but depending on the political parties. Unsurprisingly, the two main parties (the Socialist party and the right-wing party in France, the Labour Party and the Conservatives in the UK) are the biggest spenders in both countries.

\section{[Table 2 about here.]}

Spending with respect to the limit Table 2 also shows that, on average, candidates spend less than the spending limit, both in the UK and France. In France, this is most likely due to the rules on the public reimbursement of campaigns, which is limited to $47.5 \%$ of the spending limit: candidates who rely heavily on their personal money may be unwilling to spend more. But the fact that spending is also lower than the spending limit in the UK and that, in France, many candidates spend less than the reimbursement limit, suggests more generally that they face financing constraints. This may be due to unequal access to private contributions (Cagé, 2018), but also to loans, especially in France where public reimbursement is conditional on obtaining more than $5 \%$ of the votes in the first round: many candidates could be considered too risky for banks to lend to them. Of course, the level of campaign spending being an equilibrium outcome, candidates could also consider that it is optimal to spend less than the limit.

Because different candidates are able (or willing) to spend different amounts - and can do so, inasmuch as they respect the spending limit - it thus becomes interesting to question the impact of these spending differences on the probability of being elected. Figure 1 shows the raw relationship between the proportions of total spending and total (first round) votes received by candidate by district. The correlation is positive for all the elections under consideration, and most of the time the relationship seems to be well approximated by a straight line. Obviously, correlation does not imply causality, and one of the goals of this article is to determine the extent to which this relationship is causal and to quantify the magnitude of the effect.

[Figure 1 about here.]

Spending categories Political campaigning can take a number of different forms. Online Appendix Figures E.4 and E.5 report the share represented by the different spending categories in France and in the UK 13 While official denominations vary from one country to the other, the broad categories appear similar: aside from the cost of direct propaganda (even if both France and the UK forbid buying broadcast media time, they allow paper- or internet-based advertising), campaign money pays staff, political intelligence, events, administration and logistics.

For both French and UK elections, the largest disbursement item is print advertising. In the UK, it represents more than four-fifths of the total amounts spent; in France one half, the difference

\footnotetext{
${ }^{13}$ Unfortunately, this information is not available at the candidate level in France; we draw here on the summary statistics published since 2007 by the CNCCFP. In the UK, categories slightly changed between 2001 and 2010, and no data is available for 2005 .
} 
being compensated by more "Research" and "Other" spending. Perhaps surprisingly, expenditures on meetings in both countries only represent a relatively small share of the totals. 14

Sources of funding One highly useful feature of French campaign finance data (in comparison to the UK, for instance) is that it records the source of each candidate's revenues. More precisely, our data distinguish between (i) private donations (that can come both from individuals and legal entities before the 1995 ban); (ii) party contributions; (iii) contributions in kind; (iv) personal contributions; and (v) other sources.

Online Appendix Table D.3 provides summary statistics on the relative importance of these different sources of funding (online Appendix Figure E.6 plots their evolution over time). Overall, candidates' revenues come mainly from their own personal (often borrowed) funds $(52.1 \%$ ) and party contributions (25.8\%). A significant share also comes from private donations (15.5\%) 15 . Online Appendix Table D.4 shows that these amounts vary significantly depending on the political party fielding the candidate: private donations, for instance, represent a much higher share of funding for the right-wing party candidates $(26.3 \%)$ than for the candidates of the other parties. The difference with the Socialist party is statistically significant at the $1 \%$ level, even though private donations are relatively more important for them (17.1\%) than for the Communist (11.9\%), Green (5.4\%) and extreme-right (1.1\%) parties. Standard deviations also indicate that, even within the same party, sources of revenues vary significantly from a candidate to another - this will prove useful for our instrumental variable strategy.

\subsubsection{Data on candidates' characteristics}

For all the candidates included in our dataset, we determine their political party. In the UK, this information is included in expenses reports; for France, it comes from the newspaper Le Monde $\sqrt{16}$ We also infer candidates' gender from their first name. Finally, we collect information on the candidates' political mandates. In the UK, we use the Times Guide to the House of Commons to identify the candidates who was a member of a local council, the European Parliament, or a House of Common's Cabinet (see Cagé and Dewitte, 2020). For France, we determine whether the candidate was mayor, senator, departmental councilor, member of the European Parliament and government minister using

\footnotetext{
${ }^{14}$ Note, however, that this might be a feature specific to local elections. At French presidential elections, for instance, meetings are the main expenditure category (Cagé 2018).

${ }^{15}$ Unfortunately, we only have data on the total amount of private donations received, not on the number of donors and their individual contributions. Vanberg (2008) develops a model in which the composition of a candidate's campaign budget matters. Using data from the US Congress, Dharmapala and Palda (2002) find a negative relationship between the concentration of contributions and vote share. For a formal model of small campaign contributions, see in particular Bouton et al. (2018).

${ }^{16}$ In the electoral data made public by the Interior Ministry, information on candidates' political parties is often missing, imprecise or incomplete. In contrast, journalists at Le Monde, since the 1980s, have done a very detailed job at classifying each candidate depending on her party. We thank the newspaper for agreeing to share this information with us. In the online Appendix Section B, we detail for each election the list of the parties running, the coalitions at play, and how we classified parties when ambiguous. Note that we use the broad denomination "right-wing party" for the main right-wing party in France given it kept changing its official name during our period of interest
} 
different data sources.

For the municipal elected offices, we compute and rely on the municipal elections results. For the senatorial and departmental elections, we recover a list of all the elected representatives since 1990 with the exact dates of their offices from the Senate's official website. For the members of the European Parliament, we obtain a list of all the elected members by year of election from the Ministry of the Interior. Finally, for Ministers, the data were scraped from Wikipedia, assuming that all the politicians that have served as minister have a Wikipedia article. Online Appendix Table D.5 presents descriptive statistics for the candidate-level controls.

\subsubsection{District-level controls}

Finally, we collect time-varying district-level socio-demographic covariates. The main sources for these data are the official Censuses, published by the national statistical agencies (INSEE for France, and ONS in the UK). In France, we took those of 1990, 1999, 2008, 2013, and 2017; in the UK, those of 1991, 2001 and 2011 (the most recent). For each of these years, we compute the share of the population by age group, occupation and degree, and then interpolate (or extrapolate, for the UK elections after 2011) both the numerator and denominator to obtain election-year data using a natural cubic spline (Herriot and Reinsch, 1973). We also control for the annual number of firms, of employees, as well as, in France, the share of the employees who are part of the top $1 \%$ of the income distribution. In the UK, these are from the "Business Register and Employment Survey", and in France, from the "Déclaration Annuelle de Données Sociales" (DADS).

Finally, in our preferred specification, our vector of district-level controls also includes measures of electoral competition (margin at last election and number of candidates running), as well as the total spending per elector in the district and the number of registered voters. Online Appendix Table D.6 presents summary statistics for these controls.

\section{The impact of candidates' spending on vote shares}

Investigating the impact of campaign spending on votes in France and the UK presents two main empirical challenges: first, the multiparty nature of their electoral systems, and second, the endogeneity of campaign spending. In this paper, we thus develop three different empirical strategies to deal with these issues: the first strategy is the most tractable and exploits fixed effects and control variables to generate average estimates across all candidates and constituencies (Section 3.1); it allows for the use, as a second strategy, of an instrumental variable for campaign spending that alleviates the endogeneity concerns (Section 3.2); the third strategy is then designed to exploit the multiparty structure of our data and obtain by-party estimates (Section 3.3. 


\subsection{Baseline estimations}

\subsubsection{Empirical strategy}

Let vote share ${ }_{c m t}$ denote the proportion of the vote in district $m(m=1, \ldots, M)$ and election $t$ for candidate $c(c=1, \ldots, C)$. As noted by Katz and King (1999), two fundamental features of multiparty voting data are that each proportion falls within the unit interval:

$$
\text { vote share }_{c m t} \in[0,1] \text { for all } m \text { and } c
$$

and that the set of vote proportions for all the parties in a district sums to one:

$$
\sum_{c=1}^{C} \text { vote share }_{c m t}=1 \text { for all } m,
$$

i.e., within a district, candidates' vote shares are interdependent. A good statistical model of multiparty voting data should thus satisfy both equations (1) and (2). As detailed below, the two main empirical models we propose in this paper deal with the first constraint by applying a logit transformation on the vote shares. They vary in their approach to the second constraint according to their objectives ${ }^{17}$

First, to estimate the average effect of candidates' expenditures on vote shares, we rely on the literature on discrete choice models 18 We extend the Conditional Logit model (see e.g. Alvarez and Nagler 1998), which can accommodate characteristics of the choices (i.e. the candidates) available to the voter. Formally, for a choice among $\mathrm{c}(c=1, \ldots, C)$ candidates with observed characteristics $\mathbf{X}_{c}$ (among which her spending, but also her party or other personal characteristics), the utility of an individual $i$ choosing the candidate $c$ is $U_{i c}=\mathbf{X}_{i c} \beta+\epsilon_{i c}$, where the $\epsilon_{i c}$ are drawn from a type-I extreme value distribution and are uncorrelated across choices and individuals. We can then define the probability that an individual $i$ chooses candidate $c$ by:

$$
P_{i c}=\frac{\exp \left(\mathbf{X}_{i c} \beta\right)}{\sum_{k} \exp \left(\mathbf{X}_{i k} \beta\right)}
$$

To estimate this probability, discrete choice models take its log ratio with a reference choice probability $P_{i 0}$, so that: 19

\footnotetext{
${ }^{17}$ The common strategy of the campaign spending literature since Jacobson (1978) in that regard has been to estimate only one equation per district, regressing incumbent vote shares on both challenger's and incumbent's spending. In a two-party setting, this would indeed capture all available information; in the presence of more than two (effective) parties, however, it is rendered impossible.

${ }^{18}$ As a matter of fact, these models have been extensively developed by the applied IO literature, which faces empirical challenges similar to ours when it comes to estimating the impact of product characteristics (mostly price) on interdependent, aggregate, market share (see e.g. Berry et al. 1995; Nevo 2000). Much like these settings, this approach also allows us to give some structure to how we think about the effect of campaign spending at the individual level.

${ }^{19}$ Note that the main issue with this development is that it relies on the assumption that the ratio of the probabilities of choosing alternative $c$ to alternative $c^{\prime}$ for voter $i$ is independent of the probability of choosing the other alternatives (Independence of Irrelevant Alternatives). Our second empirical model relaxes this assumption (see section 3.3.
} 


$$
\ln \left(P_{i c}\right)-\ln \left(P_{i 0}\right)=\left(\mathbf{X}_{i c}-\mathbf{X}_{i 0}\right) \beta+e_{c}
$$

Given that only aggregate voting data is available (we do not have information on the voting choice of each individual voter), our strategy, in the spirit of Berry et al. (1995), is to approximate this probability with the proportions associated with each choice: in our context, the number of votes obtained by each candidate $c, s_{c}$.

$$
\ln \left(s_{c}\right)-\ln \left(s_{0}\right)=\left(\mathbf{X}_{i c}-\mathbf{X}_{i 0}\right) \beta+e_{c}
$$

This gives us, for each district, $C-1$ estimable equations (3). Because we want to estimate the coefficient $\beta$ over all candidates and districts, we define the choice 0 as the "outside option" of electors, which, in non-compulsory voting systems, is to abstain. We assume, without loss of information, that $\mathbf{X}_{0}$ is equal to zero 20 We thus estimate the following model:

$$
\ln \left(\frac{s_{c m t}}{s_{0 m t}}\right)=\alpha+\beta \text { spending share }{ }_{c m t}+\mathbf{X}_{\mathbf{m c t}} \delta+\mathbf{W}_{\mathbf{m t}} \gamma+\mathbf{Z}_{\mathbf{c}} \kappa+\zeta_{m}+\omega_{j t}+\epsilon_{c j m t}
$$

where $c$ indexes the candidates, $j$ the political parties, $t$ the electoral years and $m$ the electoral districts. $\ln \left(\frac{s_{c m t}}{s_{0 m t}}\right)$ is the logarithm of the ratio of the number of votes obtained by candidate $c$ in district $m$ in election $t$ over the abstention in district $m$ in election $t$ 21

Campaign spending is measured by spending share ${ }_{c m t}$, i.e. candidate $c$ share of the district $m$ total spending in electoral year $t$ (or, as an alternative, her absolute spending per elector). The vector $\mathbf{X}_{c m t}$ contains the other time-varying candidates' characteristics which could affect voters choice (such as incumbency or previous political mandates), and the vector $\mathbf{Z}_{c}$ the candidates' characteristics that are constant over time (such as their gender).

To account for the fact that voters' preferences can depend on their own characteristics or those of the district they live in, the vector $\mathbf{W}_{m t}$ contains the time-varying district-level covariates described above and $\zeta_{m}$ denotes fixed effects for electoral districts. We also capture the national popularity of political parties and the election-specific factors with $\omega_{j t}$, party-election fixed effects. Standard errors are clustered at the district level.

Besides, an interesting feature of our relatively long panel is that it allows us to follow candidates over time. Hence, in some specifications, we estimate the model controlling for individual candidate

\footnotetext{
${ }^{20}$ Note that it still allows abstention to vary depending on other candidates' and districts' characteristics, which we will control for.

${ }^{21}$ While this outcome variable might not seem intuitive at first sight, we argue that it is not harder to interpret than having another party as the reference category, a common practice with this conditional logit framework. Most importantly, it allows us to estimate the average impact of spending on votes across all parties (including the one that would have been chosen as "reference") and in all districts (including those where the "reference party" would not have run). Note however that, even if we argue that it would be incorrect from a statistical perspective, we show below (online Appendix Table D.10) that performing our regressions with vote shares as the dependent variable does not affect our main findings.
} 
fixed effects. This allows us to go a long way towards capturing the candidate-level heterogeneity, which has been argued to be the main driver of the endogeneity of campaign spending. In this case, the specification becomes:

$$
\ln \left(\frac{s_{c m t}}{s_{0 m t}}\right)=\alpha+\beta \text { spending share } \operatorname{smt}+\mathbf{X}_{\mathbf{c m t}} \delta+\mathbf{W}_{\mathbf{m t}} \gamma+\xi_{c}+\omega_{j t}+\epsilon_{c j m t}
$$

The identifying assumption here is that the candidates' quality is constant over time conditionally to the electoral "popularity" of their political party in a given year. The main caveat of this specification is that we have to limit our sample of analysis to those candidates who run multiple times - which, arguably, differ from the pool of all candidates.

Note that the main objective of these discrete choice models is to characterize and identify the determinants of individual voters' choices, not to understand the optimal strategies of candidates evolving in strategic environments. Recent papers such as Acharya et al. (2019) make interesting progress in that direction. In our setting, we simply assume candidates want to maximize their probability of winning given some cost of fundraising, and idiosyncratic and contextual (district) factors. This probability depends on the spending behavior of other candidates, which is why our preferred specification uses candidates' spending shares rather than level.

\subsubsection{Results}

Table 3 presents the results 22 Across all specifications and elections, a one-percentage-point increase in a candidate's share of the total spending is associated with a positive and statistically significant increase in the ratio of the number of votes obtained by the candidate over abstention. Absent any control (Column (1)), this increase amounts to $6.4 \%$ in the case of French legislative elections (Table 3a and 3.1\% for UK general elections (Table 3b, 23 These magnitudes only slightly decrease (or remain unchanged) when we introduce district-level controls (Column (2)), and candidate-level controls (Column (3)).

Introducing candidate fixed effects roughly halves the estimated coefficients. According to our most demanding (and preferred) estimation with candidate fixed effects and election-party fixed effects (Column (5)), a one-percentage-point increase in the spending share of the candidate is associated with a $1.9 \%$ (respectively $1.4 \%$ ) increase in the ratio of the number of votes she obtained over abstention in French legislative elections (respectively UK general elections). Part of this drop is due to candidate selection, given not all candidates run multiple times: we obtain a $5 \%$ (resp. 2.3\%) increase when controlling for district fixed effects with the same sample of multiple times candidates in France (resp. in the UK) (Column (4)). Most of the decrease, however, is due to the introduction of the candidate

\footnotetext{
${ }^{22}$ We do not report the coefficients for the controls in the table for the sake of space and readability. They are reported in the online Appendix Tables D.7 and D.8 We consistently find in all the specifications that being the incumbent is positively associated with the vote shares obtained by the candidates.

${ }^{23}$ In Section 4 we perform counterfactual estimations that provide estimates that are more straightforward to interpret in terms of euros-for-a-vote.
} 
fixed effects per se, i.e. the fact that in Column (5) we control for candidates unobserved characteristics that are constant over time.

[Table 3 about here.]

\subsubsection{Robustness}

In the online Appendix Table D.9 we show that these findings are robust to using the absolute amount spent by each candidate (normalized by the number of registered voters) as our main explanatory variable of interest (rather than their share of the total district spending). In doing so, we also control for the candidate's spending-squared to capture the fact that the marginal returns from spending may be decreasing (see e.g. Green and Krasno, 1988, Gerber, 1998, de Figueiredo et al., 2011). We find that, for all elections, there is a positive relationship between the total amount spent by a candidate (normalized by the number of registered voters in her electoral district) and the share of the votes she obtains. The squared terms are negative, suggesting decreasing marginal returns are also a reality in French and UK elections. We further discuss this in Section 5

In the online Appendix Table D.10, we show that our findings are robust to using, as the dependent variable, candidates' share of votes instead of share of votes-on-abstention. Doing so does not affect the statistical significance of our estimates and barely affects their magnitude. Table D.11] shows that our results for France are robust to dropping candidates who obtain less than $1 \%$ of the cast votes (we check that this is the case because of the change in the reporting requirement rules since the 2012 elections in France, given since then those candidates no longer have to report their spending).

Finally, online Appendix Table D.12 shows that our results are robust to dropping the 2017 French legislative elections. These elections were the scene of a wholesale "recomposition" of the French political landscape, following the elimination in the first round of the Presidential elections of the two main political forces that have governed France for decades (the "Parti socialiste" and the right-wing party - at the time called "Les Républicains") and the rise of two newly created political parties ("La France Insoumise” and President Emmanuel Macron's "La République en Marche”). The appearance of these two new parties makes it impossible for us to use the 2017 election in the multiparty-approach part of the paper below (Section 3.3). Hence it is important to make sure that they are not driving the results of Table 3a Reassuringly, the results we obtain when we focus on the 1993-2012 elections only are consistent with the ones presented above.

\subsection{IV estimation}

Determining the causal impact of spending on votes is rendered difficult by the endogenous nature of these campaign spending. This endogeneity arises in particular from the fact that the quality of a candidate is hard to quantify empirically, and yet is likely to correlate with both spending and votes.

The resulting bias could be both upwards and downwards. On the one hand, high-quality candidates 
are likely to receive a higher share of the votes and have higher levels of campaign contributions

- hence expenditures -, which would lead to overestimate the effect of spending on votes 24 On the other hand, the effect may be underestimated if low-quality candidates - or those suffering from a loss in popularity - extensively use campaign spending to try to compensate their deficit, while high-quality/popular candidates could rely on other strategies.

One way to overcome this issue is to use the fact that the same candidates run multiple times: this is what we do in the previous section. We find that adding candidate fixed effects significantly decreases the magnitude of the estimates, highlighting the importance of candidates' unobserved time-invariant characteristics. However, while a statistically significant and economically meaningful correlation persists when we do so, it could still be driven by time-varying candidate correlates, such as popularity. Hence, in this section, we leverage our panel data on French candidates' sources of campaign money to build an IV strategy that will single out the variation in votes that is solely driven by changes in spending.

\subsubsection{Empirical strategy: using a change in legislation}

Our strategy is based on a change in French campaign finance regulation. In 1995, France enacted a law prohibiting candidates from accepting donations from legal entities (as opposed to individuals). This law was applied for the first time for the 1997 legislative elections, which were unexpected: although the next legislative elections were not due until May 1998, President Jacques Chirac decided to dissolve the National Assembly in April 1997. Caught by surprise, candidates had little time to raise campaign funds - which usually occurs over the year before the election -, especially when they had to search for new sources. Figure 2 illustrates that candidates who relied on donations from legal entities in 1993 were thus not able to fully recover from the ban. On average, an additional euro received from legal entities in 1993 is associated with a $€ 0.6$ decrease in total revenues between 1993 and 1997.

[Figure 2 about here.]

Interestingly for us, Figure 2 also suggests that there was a strong heterogeneity in how much candidates were relying on corporate donations. This is detailed in Table 4 . While the average amount of private donations received from legal entities in 1993 was $€ 8,079$ (on average $12.4 \%$ of the candidates' total revenues, and $22.5 \%$ of their revenues from private sources), the median was $€ 0$. More precisely, of the 5, 115 candidates who ran for the 1993 legislative elections, 3, 431 (67\%) received no private donations from legal entities; while for the 1,684 candidates receiving at least some, the average amount received was equal to $€ 0.39$ per eligible voter, and represented $67 \%$ of all the private donations they received.

[Table 4 about here.]

${ }^{24}$ Similarly, higher spending could correlate with other, less measurable, drivers of campaigns, such as their number of volunteers or the quality of their organization. 
The idea of our instrumental variable strategy is thus to instrument the change in candidates' campaign spending between the 1993 and the 1997 legislative elections by the amount of donations they received in 1993 from legal entities. Our exclusion restriction is that these donations have no direct effect on the change in the votes obtained by the candidate between 1993 and 1997, conditional on the control variables, which, as before, include a set of constituency- and candidate-level fixed-effects and covariates.

There were underlying reasons why the amounts received from legal entities varied from one candidate to another. In particular, online Appendix Table D.13 shows how it depended on the political parties: the right-wing party and - to a lower extent - the Socialist party take the lion's share. To ensure the validity of our exclusion restriction in that context, we first show that our results hold in an analysis "within-party" - i.e. using candidates from only one party. Then, we confirm these results with a nearest-neighbor matching estimation, thereby accounting for all observable differences between "treated" and "control" candidates 25 . Second, to counter the possibility that unobservable correlates of corporate donations interact systematically with the change in vote shares of the candidates, we show through a series of placebo estimations that our instrument does not affect past changes in electoral outcomes. We finally try to quantify the potential bias due to these unobservables using Oster (2013) method based on selection from observables.

\subsubsection{Baseline}

Candidate-level analysis Our main analysis focuses on the 1,517 candidates who ran in both elections under an identifiable party label - i.e. $25 \%$ of all the candidates present in 1997.26 Of these, 768 candidates $(53 \%)$ received no donations from legal entities in 1993, while the others received at least some. We estimate the following two equations:

$$
\Delta_{93,97} \text { Spending share }{ }_{c}=\alpha_{1}+\beta_{1} \text { Donations legal entities }_{c 93}+\mathbf{X}_{\mathbf{c 1 9 9 7}} \gamma_{\mathbf{1}}+\zeta_{m}+\eta_{j}+\epsilon_{c m t}
$$

$$
\Delta_{93,97} \ln \left(\frac{s_{c m}}{s_{0 m}}\right)=\alpha_{2}+\beta_{2} \Delta_{93,97} \text { Spending } \text { share }_{c}+\mathbf{X}_{\mathbf{c 1 9 9 7}} \gamma_{\mathbf{2}}+\zeta_{m}+\eta_{j}+\epsilon_{c m t}
$$

where $c$ indexes the candidates, $j$ their political party, $t$ the electoral year and $m$ as before the district. $\Delta_{93,97}$ Spending share ${ }_{c}$ is the difference between the share of spending represented by candidate $c$ in

\footnotetext{
${ }^{25}$ One could indeed conceptualize our specification as a natural experiment where a group of individuals (those receiving corporate donations in 1993) receives a treatment (a decrease in their campaign spending). What prevents us from using a Difference-in-Difference approach, however, is that, given we are in a dynamic election-to-election setting, both treatment and controls groups experience endogenous entry and exit (of candidates/parties) in previous and later periods, making it hard to provide meaningful tests of the parallel trends assumption.

${ }^{26}$ To reduce the information loss and improve the external validity of our findings, we perform below a similar analysis but at the party-district level. Doing so does not alter our results.
} 
1993 and in 1997. $\mathbf{X}_{\mathbf{c 1 9 9 7}}$ is a vector including the candidates' characteristics in 1997, and $\eta_{j}$ and $\zeta_{m}$ denote respectively fixed effects for political parties and electoral district. To control for pretrends, in some specifications, we also include the vote share obtained by the candidate's party in the electoral district in 1988 as an explanatory variable. In the first stage (equation (6)), Donations legal entities ${ }_{c 93}$ is the amount of donations from legal entities per registered voter received by candidate $c$ in 1993 .

The 2SLS estimates are reported in Table 5a. The first stage estimates are reported in Columns (1) to (4), and the second stage estimates are reported in Columns (5) to (8). The first stage shows that the donations received from legal entities in 1993 by candidate $c$ in district $m$ are strongly correlated with the change in the share of the total district spending represented by the candidate between 1993 and 1997. As expected, candidates who receive more donations from legal entities in 1993 spend relatively less in 1997: we find that $\mathrm{a} € 1$ increase in the amount of donations from legal entities per registered voter received by a candidate in 1993 leads to a 6.1 to 6.9 percentage-point decrease in the candidates' share of the total district spending. We also report tests of the instrument: in all specifications, the Kleibergen-Paap LM test rejects the null hypothesis that the equation is under-identified. The weak instrument statistics also exceed the Stock and Yogo (2005) tabulation, suggesting that weak instrument is not a concern here.

The second stage results show that there is a statistically significant positive effect of spending on votes. A one-percentage-point increase in the change in the total spending share represented by a candidate between 1993 and 1997 leads to a 0.5 to $0.9 \%$ increase in the change in the vote share obtained by this candidate. The results are robust to controlling for the candidate-level characteristics as well as for the candidate's party vote share obtained in 1988 in the electoral district ${ }^{27}$

What is the magnitude of the IV estimates compared to that of the OLS estimates in similar (first difference) specifications? In the online Appendix Table D.14, we present the results of the estimation of equation (7) but with the observed rather than the instrumented change in the spending share as our main explanatory variable of interest. When we do so, we obtain estimates that are of similar magnitudes than the IV estimates ( 0.6 to $0.8 \%$ ). It should be remembered that in our candidate fixed effects framework, the IV strategy was aimed at reducing the bias due to time-varying characteristics. Hence, the fact that introducing candidate fixed effects strongly reduces the magnitude of the estimated coefficient (see Table 3a above) but instrumenting spending does not indicates that, from a campaign spending point of view, time-invariant unobserved characteristics seem to matter more than those varying over time.

[Table 5 about here.]

Analysis at the party level As suggested, the main issue with the above empirical strategy is that, because we need candidates to have run in both the 1993 and 1997 elections, we are left with only

\footnotetext{
${ }^{27}$ In the online Appendix Table D.15, we show that our results are robust to considering the amount spent by each candidate rather than the share of the total district spending as our main outcome of interest.
} 
1, 517 candidates, losing nearly four-fifths of our sample. Moreover, the candidates who ran in both 1993 and 1997 are not representative of all the candidates running in 1997 (online Appendix Table D.16): they have a higher probability of holding other mandates (such as mayor and departmental councilor), of being male, and of spending more.

Hence, as an alternative empirical strategy, we estimate equations (6) and (7) at the party rather than at the candidate level, i.e. we attribute all the donations received by a candidate and the amount she spent to her political party in her district. This only requires the political party - and not the candidate - to be present in the electoral district both in 1993 and 1997, which is far more systematic. Table 5 b presents the results. They are consistent with those we obtain in Table 5a, if anything, the magnitude of the estimated effects is larger.

\subsubsection{Robustness: within-party analysis and matching}

Analysis within party As highlighted above, candidates receiving legal entities' contributions in 1993 are not equally spread across parties. Hence, in order to further improve the comparability between candidates and make sure that political parties' fortunes do not violate our exclusion restriction, we start by performing the above analysis restricting our sample to, first, the right-wing party candidates (who benefited most from donations from legal entities before their prohibition) and, second, the Socialist candidates - the other major party. Table 6 presents the results. As before, we obtain a positive and statistically significant effect of the instrumented change in spending on the change in vote share - a result that is particularly striking given the low number of observations.

[Table 6 about here.]

Matching Next, we estimate the sample average treatment effect of corporate donations with a nearest-neighbor matching estimation (Abadie and Imbens, 2006). The idea here is to match 1997 legislative elections candidates who received corporate donations in 1993 with candidates who did not but are "similar" on all other observable dimensions. Specifically, we match observations with replacement on political parties, other candidate-level controls (gender and political mandates), and our usual set of district covariates. In all specifications, we estimate the bias-corrected treatment effect of Abadie and Imbens (2011). Table 7 shows our results. We find that the reliance on corporate donations in 1993 is associated with a decrease in the vote share obtained by otherwise "similar" candidates between the 1993 and 1997 legislative elections. This result holds even when we match both on candidates' and districts' characteristics.

\section{[Table 7 about here.]}

Placebo tests Could there be unobservable dimensions correlated with the level of corporate donations that interfere systematically with the change in votes for candidates between 1993 and 1997 ? 
While one can never fully rule out that possibility, we think it is very unlikely for the following reasons.

First, we show in Table 8 that our instrument does not impact electoral results at previous elections - which is akin to a placebo test 28 Upper Table 8 a focuses on the change in vote shares between 1988 and 1993, and bottom Table 8b between 1981 and 1988. In both tables, Column (2) reports the impact of the instrumented spending estimates for our baseline subset of candidates (running both in 1993 and in 1997) on the change in the votes obtained by their party at previous elections 29 Reassuringly, in both cases, we find no impact of the instrumented change in spending on results at previous elections, with estimates that are not statistically different from 0 .

Given that parties of the candidates running in 1993 and 1997 did not sytematically nominated candidates in the same districts at previous elections, the sample size is reduced by around $30 \%$ (respectively 60\%) when we consider the 1988-1993 (1981-1988) changes in votes. Hence, to make sure our results are not driven by this sample change, we report in Column (3) our baseline estimates using these smaller samples: reassuringly they remain similar, though slightly smaller, than the estimates presented in Table 6 Altogether, this suggests that correlates of corporate contributions do not usually interfere with votes when controlling for all our parties, districts and candidates observable dimensions.

[Table 8 about here.]

Could the 1997 elections be different? An intuitive unobservable one often links to levels of corporate contributions is the quality or valence of the candidates. But nothing in the qualitative accounts of the elections suggest a sudden rupture in electors' valuation of quality between 1993 and 1997. The score of extreme parties (which are often an indicator of public resentment towards traditional elites) was stable (e.g. the Front National national results increased by $2.5 p p$, the same increase than the one observed between 1988 and 1993). In fact, 1997 is rather characterized by the shift of power from the main right-wing to the main left-wing parties amid deception of President Chirac reforms.

Another hypothesis could be that electors suddenly felt a direct animosity towards corporate political involvement. But sources of campaign contributions are in fact rarely disclosed during elections, nor analyzed at the individual level afterwards, so that few electors actually know about them. This makes very unlikely for this channel to be systematic.

Using selection on observables to assess the bias from unobservables As a final exercise to ensure that our results can be interpreted as, at least partially, causal, we use insights from Altonji et al. (2005)

\footnotetext{
${ }^{28}$ It would be interesting to look at past occurrences of our instrument but, as noted before, campaign contribution data only start in 1993. Besides, we would actually not argue that the level of private donations in previous years should not have an impact on candidates' subsequent results; the difference in our setting is that the reform of 1995 makes this impact exogenous.

${ }^{29}$ Given the number of candidates who run not only in 1993 and 1997 but also in 1988 and 1981 is too small, we need to rely here on results at the party rather than at the candidate level.
} 
and Oster (2013) to quantify the potential bias due to unobservables, using the sensitivity of the effect to added (observable) controls.

The idea is the following (see the online Appendix Section $\mathrm{F}$ for the detailed development). Let $\delta$ be a measure of the correlation between observed and unobserved covariates of equation (5). Define the ratio $B(\delta)=\delta \frac{(\xi-\Lambda)\left(R_{\max }-R_{2}\right)}{R_{2}-R_{1}}$ where $R_{\max }$ is the R-squared of the full model regression; $R_{2}$ the R-squared of the regression including all the observed covariates; and $R_{1}$ the R-squared of a regression including only a restricted set $M$ of observabe covariates. Under the Proportional Selection Assumption 30 and with $\delta$ close enough to one, $B(\delta)$ provides lower (if $\delta>1$ ) and upper bounds (if $\delta<1$ ) of the bias due to unobservables (Oster, 2013). We can then measure the importance of this bias by comparing it with our main estimated coefficients.

First, one needs to determine the true value of $R_{\max }$. Because there is probably some randomness in the movements of the outcome, it is unlikely to be equal to one. Oster (2013) uses the R-squared from different randomized experiments. In the campaign finance literature studying the effect of campaign expenditures, the R-squared rarely exceeds 0.3 and are usually close to 0.2 (below 0.13 in Da Silveira and De Mello (2011), between 0.11 and 0.23 in Ben-Bassat et al. (2015), equal to 0.24 in Levitt(1994)). In our own regressions, the within R-squared never exceeds 0.4. We thus choose in our computations a conservative value of 0.3 .

Figure 3 plots the ratio of our main effect (as given in the Column (5) of Table 3a) over the bias $B(\delta)$ with $R_{\max }=0.3$, for different values of $\delta$ and two different restricted sets of controls $M$. We see that this ratio is higher than one. It makes it unlikely that the entire estimated effect of campaign spending is driven by unobserved variables.

[Figure 3 about here.]

\subsection{Multiparty estimation}

While allowing us to compute an average effect and to use instrumental variables, the above specifications do not provide separate estimates for each party. Katz and King (1999) propose a model that allows us to fully exploit the richness of multiparty data and, in addition, relax the IIA assumption. In this section, we thus follow Katz and King (1999) and bring the associated methodology provided by Tomz et al. (2002) to campaign spending analysis.

\subsubsection{Empirical strategy}

Our presentation here closely follows the one in Tomz et al.(2002). As previously, we convert the share of electors voting for each party $j(j=1, \ldots, J-1)$ and abstaining $(J)$ to an unbounded scale by applying a multivariate logistic transformation. We then assume that the vector of $J-1 \log$ ratios of votes on abstention in $m$ electoral district, $Y_{m}=\left[\ln \left(V_{m 1} / V_{m J}\right), \ln \left(V_{m 2} / V_{m J}\right), \ldots, \ln \left(V_{m(J-1)} / V_{m J}\right)\right]$,

\footnotetext{
${ }^{30}$ This assumption states that $\delta C_{W X}=\frac{C_{W^{\prime} X}}{V_{W^{\prime}}}$.
} 
is multivariate Normal with mean vector $\mu_{m}$ and variance matrix $\Sigma$. We model $\mu_{m}$ as a linear function of explanatory variables $\mathbf{X}$ (such as campaign spending) and effect coefficients $\beta$, such that $\mu_{m}=\left[\mathbf{X}_{m 1} \beta_{1}, \mathbf{X}_{m 2} \beta_{2}, \ldots, \mathbf{X}_{m(J-1)} \beta_{(J-1)}\right]$. Finally, to estimate $\beta$ and $\Sigma$, we use Tomz et al. (2002)'s variant of seemingly unrelated regressions (SUR) that employs the Feasible Generalized Least Squares (FGLS) algorithm.

Specifically, our empirical specification is, in the case of French legislative elections, as follows:

$$
\begin{aligned}
\ln \left(\frac{s_{\text {Communist } m t}}{s_{0 m t}}\right) & =\alpha_{1}+\sum_{j=1}^{6} \beta_{1 j} \text { spending }_{j m t}+\sum_{j=1}^{6} \delta_{1 j} \text { Incumb }_{j m t}+\mathbf{X}_{\mathbf{m t}}^{\prime} \boldsymbol{\kappa}_{\mathbf{1}}+\lambda_{1 m}+\eta_{1 t} \\
\ln \left(\frac{s_{\text {Green } m t}}{s_{0 m t}}\right) & =\alpha_{2}+\sum_{j=1}^{6} \beta_{2 j} \text { spending }_{j m t}+\sum_{j=1}^{6} \delta_{2 j} \text { Incumb }_{j m t}+\mathbf{X}_{\mathbf{m t}}^{\prime} \boldsymbol{\kappa}_{\mathbf{2}}+\lambda_{2 m}+\eta_{2 t} \\
\ln \left(\frac{s_{\text {Socialist } m t}}{s_{0 m t}}\right) & =\alpha_{3}+\sum_{j=1}^{6} \beta_{3 j} \text { spending }_{j m t}+\sum_{j=1}^{6} \delta_{3 j} \text { Incumb }_{j m t}+\mathbf{X}_{\mathbf{m t}}^{\prime} \boldsymbol{\kappa}_{\mathbf{3}}+\lambda_{3 m}+\eta_{3 t} \\
\ln \left(\frac{s_{\text {Right } m t}}{s_{0 m t}}\right) & =\alpha_{4}+\sum_{j=1}^{6} \beta_{4 j} \text { spending }_{j m t}+\sum_{j=1}^{6} \delta_{4 j} \text { Incumb }_{j m t}+\mathbf{X}_{\mathbf{m t}}^{\prime} \boldsymbol{\kappa}_{\mathbf{4}}+\lambda_{4 m}+\eta_{4 t} \\
\ln \left(\frac{s_{\text {Extreme-Right } m t}}{s_{0 m t}}\right) & =\alpha_{5}+\sum_{j=1}^{6} \beta_{5 j} \text { spending }_{j m t}+\sum_{j=1}^{6} \delta_{5 j} \text { Incumb }_{j m t}+\mathbf{X}_{\mathbf{m t}}^{\prime} \boldsymbol{\kappa}_{\mathbf{5}}+\lambda_{5 m}+\eta_{5 t} \\
\ln \left(\frac{s_{\text {Other } m t}}{s_{0 m t}}\right) & =\alpha_{6}+\sum_{j=1}^{6} \beta_{6 j} \text { spending }_{j m t}+\sum_{j=1}^{6} \delta_{6 j} \text { Incumb }_{j m t}+\mathbf{X}_{\mathbf{m t}}^{\prime} \boldsymbol{\kappa}_{\mathbf{6}}+\lambda_{6 m}+\eta_{6 t}
\end{aligned}
$$

where $t$ indexes the election, $m$ the district, and $j$ the political parties. For each party $j, \ln \left(\frac{s_{j m t}}{s_{0 m t}}\right)$ is the log ratio of the party's share of the vote in district $m$ and election $t$ relative to that of the abstaining share. We estimate the equations simultaneously via seemingly unrelated regressions.

Our main explanatory variable of interest is spending j $_{j m t}$, which is the political party $j$ 's spending per registered voter in district $m$ and election $t$. Incumb ${ }_{j m t}$ is an indicator variable equal to one if the incumbent is from the political party $j$, and to zero otherwise. The vector $\mathbf{X}_{\mathbf{m t}}$ contains the previously described district-level controls. $\lambda_{m}$ and $\eta_{t}$ denote fixed effects for electoral districts and elections, respectively.

Choosing the set of political parties Political parties do not run everywhere. When one or more parties under consideration do not run in a district, this district is considered to be "partially contested", as opposed to "fully contested". The model above only estimates the effect of spending on votes in the fully contested districts (in the robustness Section 3.3 .3 below, we discuss how we can capture information from partially contested districts as well). Hence, we need to determine the number $J-1$ of parties for which we can have a unique estimate, with a trade-off between this number and the 
number of districts entering our analysis. For France, we focus on the five political parties that have consistently presented candidates in the majority of the districts during our period of interest, namely (from the extreme-left to the extreme-right): (i) the "Parti Communiste" (PC) (or Communist party); (ii) the Green party (whose name was changed a number of times during the period); (iii) the "Parti Socialiste" (PS) (Socialist party); (iv) the right-wing party (as detailed in the online Appendix, the name of this party also changed a number of times during our period of interest); and (v) the "Front National" (FN) (National Front, the French extreme-right party). In the UK, we focus on the Labour Party, the Liberal-Democrats, the Conservative Party and the UK Independence Party (UKIP). Candidates from other smaller political parties (or without political affiliation) are entered in the "Other" category

The special case of France 2017 As highlighted above, the 2017 French legislative elections marked a turning point in the political history of the French parties. The legislative elections immediately followed the Presidential election that had seen the victory of Emmanuel Macron and the elimination in the first round of the two main political forces that had governed France for decades. This election was characterized by the appearance of two major new parties: "La France Insoumise" and Macron's "La République en Marche" (LRM). As shown in the online Appendix Table B.1] these parties fielded almost as many candidates as the "old" ones; besides, a number of candidates switched from established parties to LFI or LRM (in particular those who ran under the "Parti Socialiste" label in 2012).

These peculiarities of the 2017 legislative elections explain why we cannot treat them in the empirical analysis the same way we treat the other elections. In particular, considering LFI and LRM as separate parties, which would be the natural way to progress, would mean dropping all years but 2017 because of the "fully contested" constraint explained above. At the same time, including them in the "Other party" category would significantly alter the meaning of this category and thus the consistency of our results. Therefore, the estimations presented here are for the 1993-2012 elections. However, we show in the robustness Section 3.3 .3 below that our findings are robust to also including the 2017 elections with LFI and LRM in the "other party" category.

\subsubsection{Results}

Table 9 presents the results for the French legislative elections for the fully contested districts 32 Before turning to the across-party dynamics made visible in this analysis, let us first consider, as in the previous sections, the impact of a candidate's spending on her own votes (i.e. the diagonal numbers). We find that it is positive and statistically significant at the $1 \%$ level for all the parties: a one-euro increase in spending by the Communist party, for instance, increases the log ratio of the Communist party share of the vote relative to abstention by 0.58 . This value fluctuates between 0.35 and 1.87 for the other parties.

\footnotetext{
${ }^{31}$ Online Appendix Tables B.1 and D.17 provide information on the number of districts in which each political party fielded candidates for all the elections.

${ }^{32}$ The coefficients for the district-level controls are not reported here for the sake of space. They are reported in the online Appendix Table D.18 for France and D.19 for the UK. Note that an observation is a district-election.
} 
We explain below how these different magnitudes can be interpreted in terms of euros-for-a-vote, and what their variation can tell us about the nature of each party. Interestingly, these coefficients are of a similar magnitude as those of Table D.9 Column (3), in which we report the results of the conditional logit specification with the same spending variable (absolute spending).

[Table 9 about here.]

Table 10 presents the results for the UK general elections. Here as well, the correlation between parties' spending and their own votes-on-abstention is positive and statistically significant. One euro per registered voter increases votes-on-abstention by 0.85 to 4.63 , depending on the party.

[Table 10 about here.]

\subsubsection{Robustness checks}

Full information approach In Section 3.3.2 above, we estimated the effect of spending on votes in fully contested districts. This approach is not entirely satisfying. First, by dropping a number of electoral districts, we lose potentially useful information. Second, this might result in a nonrepresentative sample (King et al., 2001, Tomz et al., 2002). As an alternative, we follow Katz and King (1999) and Honaker et al. (2002) who address the problem of partial contest by using the effective rather than the actual vote. The effective vote is the values of vote share ${ }_{j m t}$ that we would observe if all the parties contested the election in district $m$. In districts with all parties contesting, the effective vote is equal to the observed vote. In partially contested districts, the effective vote for all parties is unobserved but can be estimated. Such an estimation can be performed under a number of reasonable assumptions, in particular that the non-contesting party would have received fewer votes than the parties that did nominate candidates (Honaker et al. 2002). We thus proceed in two stages. First, we perform five imputations - i.e. generate 5 datasets - of effective voting data in partially contested districts (using the Amelia R-package built for this purpose). Then, we perform the above SUR estimation on each of them and average the results (using Clarify statistical software).

We present the results for the legislative elections in the online Appendix Tables D.20 and D.21] We can see that the number of district-elections in our sample increased both in France and in the UK, given that the partially contested districts are now part of the analysis, rising to 2, 610 and 3,275 respectively. Reassuringly, the results we obtain are consistent with those in the Tables 9 and 10] Again, for all parties under inspection, we obtain a positive and statistically significant effect of spending on their vote shares. The magnitude of the effects is roughly the same, with point estimates varying between 0.37 and 3.01 in French legislative election, and 1.41 and 4.73 in UK general elections, depending on the political party. In particular, the magnitude of the estimates is barely changed for the smallest parties (e.g. the Communist party in France, with a point estimate equal to 0.94 in Table D.20 and to 0.58 in Table 9, or UKIP, from 2.76 to 2.25 respectively) for which we imputed votes in the highest number of districts. 
Random coefficient approach The multiparty estimation presented in this section allows us to relax the IIA assumption (on which the Conditional Logit model presented in Section 3.1 relies), but not to instrument for the endogeneity of spending. Hence, we verify here whether our findings are robust to an alternative approach relaxing the IIA and instrumenting for spending. Specifically, we estimate a random coefficient logit model (Berry et al., 1995, Nevo, 2000). Following Rekkas (2007), we assume that parties can be considered "consumption goods", whose characteristics impact the utility of voters. Candidates' spending represents the endogenous price variable, and we instrument this "price" by the district-level average of campaign spending by registered voters in the previous election, a lagged measure of the closeness of the race, and the interaction of these variables with the incumbency indicator variable, the average spending by registered voters by opposing parties in the same electoral district, and the average spending by registered voters by the same party across all other districts. The model we estimate is presented in detail in the online Appendix Section G, together with the results for the French legislative elections.

The main findings of this alternative approach are consistent with the results presented in Section 3.3.2 above. First, we show that the average coefficient on campaign spending across voters is positive and statistically significant. Second, when considering heterogeneity across political parties, we find that extreme-right candidates benefit less from increasing their campaign spending than right-wing and left-wing candidates. Interestingly, extreme-right candidates are also less affected by other parties' campaign expenditures. We do not want to give too much weight to these results given that they rely on strong assumptions, in particular regarding the instrument set we use for the price (all these concerns are detailed in Section G]. But the fact that they are in line with those of our two main empirical models gives confidence as to their empirical validity, and to a causal interpretation of the positive relationship between spending and votes.

Including the 2017 French legislative elections Finally, we show that our results are robust to including the 2017 French legislative elections. Online Appendix Table D.22 presents the results. Doing so affects neither the magnitude nor the statistical significance of our main results.

To sum up, in this section we have used three different empirical strategies to investigate the effect of campaign spending on vote shares. We have found that the impact is significant for all the elections under consideration, with similar orders of magnitudes across specifications. Further, using different methodologies, we have provided suggestive evidence that the effect of spending is not entirely driven by the endogeneity of spending with respect to votes. In the next sections, we thus use these specifications to exploit the rich heterogeneity of our data and try to understand for whom, how, and why money matters in elections. 


\section{The heterogeneous price of a vote}

\subsection{The cross-effects of campaign spending}

One of the main advantages of the approach presented above is that it allows us to investigate whether some parties suffer relatively more from the money spent by others, an issue that has not received much attention in the existing campaign spending literature 33 Spending by a party may indeed directly affect the vote shares obtained by other parties, positively or negatively, and with heterogeneous magnitudes. In that sense, investigating the cross-effects of campaign spending may thus help to improve our understanding of party closeness and/or opposition as perceived by voters. This may also contribute to the literature on stability and change in voting behavior.

We find evidence of negative cross-party effects of campaign spending, suggesting that individuals switch their votes across parties $\sqrt{34}$ In the case of French legislative elections (Table 9), the spending of Communist and Green parties is, for instance, detrimental to the votes-on-abstention of the other main left-wing group, the Socialist party. Interestingly, this effect is not systematically symmetric: the Communist party candidates do not suffer from additional spending by the Socialist party (while the Green party candidates do). The Right-wing spending is mostly detrimental to the votes of the "Other" party (and conversely), suggesting that these small parties represent an alternative for the right-wing voters. We also observe a negative effect of right-wing spending on the votes for the Green party.

However, the negative cross-effects of spending do not seem to cross the ideological spectrum for the left-wing parties: spending by the Communist and the Socialist parties do not negatively affect votes for the right or extreme-right parties; if anything they have a positive effect. This is not entirely surprising. It has indeed been documented that in two-party systems, such as the US, campaigns increasingly focus on mobilizing supporters rather than on persuading undecided voters (see e.g. Panagopoulos, 2016, Kalla and Broockman, 2018). In a multiparty context, however, this can take the hybrid form of left-leaning campaigns aimed at mobilizing voters from all left-wing parties, thus allowing a switching of votes between parties that are relatively close in ideology 35

Table 10 shows the results for the UK general elections. There, the spending of each of the three main parties (Labour, Liberal, Conservative) is detrimental to the other two - with the exception of Labour spending's impact on Conservative party's votes, which we discuss below. This suggests a

${ }^{33}$ There is a very large body of literature on the spatial positioning of political parties and their ideological proximity (among many others: Downs 1957, Adams and Somer-Topcu, 2009, Adams 2012, Williams and Whitten, 2015), but it most often uses as identifying variation the shifts in parties' policies, not in campaign spending.

${ }^{34}$ Recall that our dependent variable is the (log) votes obtained by a party divided by the abstention in the district. This common denominator means that any pure mobilization mechanism (i.e. one modifying only the abstention pool and the votes of the studied party) would translate in positive co-movements of parties' log ratios. Hence, negative co-movements necessarily indicate changes in the behaviors of voters of the other parties, whether a shift of votes or a de-mobilization.

${ }^{35}$ Note, however, that there is evidence that persuasive communication across the political spectrum may be effective. Pons (2018) evaluates the effect of door-to-door canvassing in the context of the 2012 French presidential election: he finds an increase in the vote share obtained by the Socialist party candidate (who implemented the canvassing campaign) and provides evidence that this increase is partly due to the persuasion of right-wing voters. 
relatively intense competition for voters. ${ }^{36}$ UKIP's spending has a negative effect on Labour's results but no effect on those of Conservatives, and Labour's spending negative coefficient on UKIP's votes is almost twice as large as that of the Conservatives. This goes in the direction of studies finding that the new radical-right tends to capture left-leaning, working-class voters (Dal Bo et al., 2019, Piketty, 2018).

Finally, we also find a few positive cross-effects - i.e., the spending of a party that increases the votes-on-abstention for another one. For instance, the spending of the Communist party in France improves the results of the extreme-right party. In the UK, Labour spending increases the votes for their Conservative rivals. This could reveal the existence of a "competitive" or "backlash" effect: realizing that a party against which they hold strong views is investing heavily in the campaign, voters increase their mobilization for their preferred party.

\subsection{The price of a vote and the radical parties exception}

Interpreting results in terms of changes in relative vote and spending shares is not always straightforward. In this section, we perform a number of counterfactual estimations to estimate the monetary value of an additional vote obtained by a marginal increase in campaign spending: the "price of a vote". Specifically, we assume that all candidates of one party increase their spending by one standard deviation of the average spending per registered voter $(+€ 0.28$ in the case of France and $+€ 0.07$ in the case of the UK) and estimate, everything else equal, how this impacts the vote shares. We perform this counterfactual estimation separately for each of the political parties $[37$ and then, for each of the counterfactual estimations, compute the total number of votes obtained by each party, in each district, under this assumption. We aggregate these votes at the national level, as well as the total increase in spending, and thus compute, for each electoral year, the average price of an additional vote for the party whose spending increased. This provides us with election-specific, easily-comparable estimates of the impact of campaign spending, which incorporate both own- and cross-party effects.

Figures 4 and 5 plot the results. First, we find that the price of a vote is fairly stable over time, both in France and in the UK (with the exception of the extreme-right parties, which we discuss below). This finding is not obvious. Many argue that with the introduction of new technologies, in particular the Internet, it has become increasingly cheaper for candidates to run in elections. Here, in the case of both France and the UK, we do not find any major changes in recent decades 38

We also find that the price of a vote varies depending on the political party (as suggested by the

\footnotetext{
${ }^{36}$ We do not want to conclude, however, that these cross-effects are more pervasive in the UK in relation to France, as the presence of more candidates in France could simply mean votes are exchanged across more parties, making the coefficients relatively less precise.

${ }^{37}$ Hence, we perform a first counterfactual estimation assuming that all the right-wing party candidates face a xx-euro increase in spending per voter in all districts/years, everything else equal; then a second counterfactual estimation assuming that all the Socialist party candidates face a xx-euro increase in spending per voter in all districts/years, everything else equal; etc.

${ }^{38}$ On the long-term evolution of the cost and efficiency of campaigning technologies, see Cagé and Dewitte (2018).
} 
point estimates of Tables 9 and 10]. In France, according to our estimates, the price of a vote is lowest for the right-wing party ( $€ 7$ to $€ 11$, depending on the elections). It is higher for the Green party $(€ 9-€ 19)$ and for the Socialist party $(€ 11-€ 21)$. In the UK, the party facing the lowest price on average is the Liberal Democrats, from $€ 2$ to $€ 5$, while those of the Labour and Conservative parties oscillate between $€ 4$ and $€ 8$.

Last but not least, the price of a vote is much higher for the extreme parties than for the other political parties: between $€ 27$ and $€ 59$ in France for the Communists and, most particularly, between $€ 29$ and $€ 93$ for the FN and between $€ 5$ and $€ 52$ for the UKIP. This difference is persistent through time, though it is volatile and appears to decrease in the UK.

[Figure 4 about here.]

[Figure 5 about here.]

How can we rationalize the fact that campaign spending seems to be systematically less efficient (and more volatile) for the far-right than for the other political parties?39 A first potential explanation is the existence of a social stigma attached to extreme-right voting, which makes it a priori less acceptable for citizens to campaign or vote for far-right parties (Harteveld et al. 2019a b). Because of this, it may be more difficult for extreme-right candidates to persuade undecided voters. To investigate whether this is the case, we use the fact that, for many reasons, the intensity of this stigma can vary from one electoral district to another. In France, we capture this by the results obtained by the extreme-right candidates at the last legislative elections before our period of interest (the 1988 elections). In the UK, because UKIP was created in 1993, we use their vote share at the 1999 European elections. We thus split our electoral districts using the median of these variables, and estimate equation (8) separately for low-stigma districts thus defined (online Appendix Tables D.23 and D.25) and for high-stigma districts (online Appendix Tables D.24 and D.26. We find that, in both countries, the coefficient associated with an increase in spending by the extreme-right party is higher in low-stigma districts ( 0.36 / 2.45) than in high-stigma districts $(0.31 / 1.77)$.

Second, campaign expenditures may be less efficient for extreme-right candidates because these candidates are themselves less efficient campaigners. This would be the case if these candidates suffer, for example, from a valence disadvantage. A number of models in the literature have indeed shown that low valence candidates might be driven to choose more extremist positions (see in particular Ansolabehere and Snyder, 2000, Groseclose, 2001; Aragones and Palfrey, 2002). Empirically, Cagé and Dewitte (2020) show that UKIP candidates are, on average, less educated, older and of lower

\footnotetext{
${ }^{39}$ In the following lines, we elect to focus on extreme-right parties. We do so because the fact that the results hold in both countries points towards a systematic pattern (there is no large extreme-left party in the UK). Further, these parties became extremely visible in the political arena over the period (in contrast, the French Communist Party was of smaller importance in recent years). Yet, we acknowledge it could be an "extreme-parties" phenomenon, and in fact many of the proposed explanations could also apply to the extreme-left.
} 
occupational status than candidates from other parties 40 In France, there is considerable anecdotal evidence of the fact that the extreme-right party has serious difficulty fielding quality candidates across the country in legislative elections.

The lower efficiency of campaign spending for the extreme-right may also be linked to the salience of the issues it capitalizes on; a key function of electoral campaigns is indeed to reduce voter uncertainty about the policy positions of the candidates. The extreme-right stance on issues such as immigration or Europe, for instance, is often tough and controversial; this position is well known and campaign spending may not affect citizens' knowledge of extreme-right candidates' position on those issues (see e.g. Le Bras, 2015). On the other hand, voters may be unaware of, for instance, Green party candidates' position on issues such as the development of local currencies: in that case, we could expect campaign expenditure to have a more direct, informative impact on voters.

Another related potential explanation pertains to the fact that, to the extent that individuals who vote for extreme parties may be more ideological, they would vote for the extreme-party candidates regardless of their personal characteristics 4 , making them less responsive to local campaigns. This in fact would also help us rationalize the relatively high price of a vote we observe for the extremeleft in France. Using data on parliamentary elections in Finland, Kestilä-Kekkonen and Söderlund (2014) have indeed shown that being guided by the characteristics of the party leader is a much stronger predictor of the far-right vote than being affected by district-level or candidate characteristics. Consistently with this finding, Le Pennec-Caldichoury (2019) show that in the first round of the 1993 French legislative elections, political manifestos of the extreme-right candidates tended to be similar (all following the same national model), while the manifestos of the candidates of the other parties varied at the local level, depending on the candidates' characteristics.

All these potential explanations can also help us understand why the price of a vote for the extremeright can change, and in particular decrease, over time. As extreme-right parties permeate the political landscape and experience electoral successes, the social stigma associated to their positions could fade (Bursztyn et al. 2020), and their ability to recruit better experienced candidates improve. Similarly, the rise of certain issues, such as Brexit, could transform the high salience of their positioning into a competitive advantage, or instead make them more vulnerable to issue-cannibalization by other parties.

\section{Discussion}

This last section discusses potential mechanisms behind our main findings, drawing into the large literature on campaigning, and explores how they can improve our understanding of why campaigns

${ }^{40}$ In the US, Stone and Simas (2010) show that challenger extremism results from a character disadvantage (see also Adams et al. 2011).

${ }^{41}$ For a recent review of the literature on the determinants of the far-right vote, see Stockemer et al. (2018). A large share of voters casting their ballot for the far-right are looking for ideological identification. 
matter, in France and in the UK - and consequently in other countries 42

\subsection{For whom money matters: mobilization vs. persuasion}

We have shown that money plays a role in the electoral process: by increasing their electoral spending, on average and everything else equal, candidates increase the number of votes they obtain. But how does it operate exactly? In other words, what changes does spending induce in citizens' behaviors that translate into higher vote shares? Formally, the literature identifies three potential ways in which campaigns affect voters' decisions (Herrera et al., 2008, Jacobson, 2015). First, spending can move party sympathizers to effectively vote, which is often called the "mobilization effect" of campaign spending. Second, spending can help persuade undecided voters, or voters leaning towards the other party, of the merits of another party's policies (see e.g. Acharya et al., 2019, Prat, 2002a b; Schultz, 2007). This is the "persuasion effect" of spending. Finally, campaign spending can be used to dissuade sympathizers of the other party from voting. The multiparty analysis of the previous section already suggested the existence of persuasion dynamics: when candidates from specific parties spend money, it decreases the amount of votes cast for candidates from some other parties. This section leverages the heterogeneity of our data to see whether mobilization mechanisms are also at play.

Voter characteristics One way to distinguish between mobilization and persuasion effects of campaign spending is to rely on the fact that, as highlighted by Jacobson (2015), "campaigns matter, but not for everyone". One can indeed expect citizens to vary in their susceptibility to persuasion by political campaigns: it has been argued for instance that electors with low education lack strong political awareness and are more sensitive to political advertising (Zaller, 1992) - and hence to campaign spending. At the same time, recent studies show that campaigns aimed at increasing mobilization have larger effects on the populations that are already more likely to turn out, such as high social-economic groups (Enos et al. 2014): in that case, we would expect education to be positively correlated with the impact of spending.

We test these assertions by estimating equation (4) separately for electoral districts that are above and below the median district in terms of the share of the population with higher education levels. Online Appendix Table D.27presents the results. For both countries, the correlation between spending and votes appears significantly higher in more educated districts. In Table D.28, we perform a similar analysis with the share of white-collar workers (similarly splitting our sample between districts that are above / below the median). Similar to education, we find a (slightly) higher effect of spending in higher occupational-status constituencies, for both French legislative and UK general elections. 43

\footnotetext{
${ }^{42}$ Mostly suggestive, it should be taken first and foremost as a set of hints for more systematic research on the topic, whether using our data or other settings.

${ }^{43}$ Note that these findings contrast with those of Larreguy et al. (2018) in Mexico and Da Silveira and De Mello (2011) in Brazil, who find a higher impact of campaigns in less-educated neighborhoods. This could be rationalized by the fact that in these countries the median levels of political awareness and education could be very different than in France and the UK.
} 
Evidence hence leans towards mobilization here.

Turnout An even more direct way to test whether campaigns have a mobilization effect is to investigate the impact of spending on turnout. We do so using the following empirical specification:

$$
\text { turnout }_{m t}=\alpha+\beta \text { total spending }{ }_{m t}+\mathbf{X}_{\mathbf{m t}}^{\prime} \kappa+\zeta_{m}+\eta_{t}+\epsilon_{m t}
$$

where, as before, $t$ indexes the election and $m$ the district. The outcome of interest, turnout ${ }_{m t}$, is the share of electors who cast their vote. total spending ${ }_{m t}$ is the total amount spent by candidates (per registered voter) in district $m$ and election $t$. We consider alternately this aggregated variable and the spending of the different political parties taken individually. The vector $\mathbf{X}_{\mathbf{m t}}^{\prime}$ contains the same district-level controls as before. Standard errors are clustered at the district level.

Table 11 presents the results. The correlation is relatively small, but significant: a one standarddeviation in total spending by candidates increases turnout by around 0.045 (respectively 0.074 ) standard-deviation in French legislative elections (respectively UK general elections). Of course, these results should be considered carefully given that they are just correlations - they could be, for instance, driven by parties intentionally spending more in districts where they anticipate a high participation. But they are consistent with previous findings in the literature, such as those regarding the positive impact of door-to-door canvassing on voter turnout (see e.g. Gerber and Green (2000) or Panagopoulos and Green (2008) for a review), and suggest, at least, that we cannot rule out the existence of a mobilization effect of campaign spending in our context.

[Table 11 about here.]

Interestingly, the effect of spending on political participation strongly varies depending on the political party. It is the highest for the main left-wing parties (Socialist and Labour), and decreases steadily towards the right end of the political spectrum. UKIP spending has no influence on turnout, while the spending by the extreme-right party in France has a negative impact on turnout.

\subsection{Why money matters: information vs. deterrence}

Information and newspaper penetration Whether campaign spending mobilizes or persuades still does not fully explain why it matters - i.e. what aspects of spending mobilize or persuade. One potential channel is information provision. A key function of electoral campaigns is indeed to reduce voter uncertainty about the policy positions and characteristics of different candidates (Lenz, 2009; Peterson 2009). Hence campaign spending may simply play a role by providing voters with this information (see e.g. Baron, 1994, Coate, 2004a b). This would be in line with the fact that, as shown in Section 2.2.2, the main category of candidates' disbursements is, both in France and the UK, print 
advertising (e.g. expenditures on printed leaflets and posters) ${ }_{44}^{44}$

In that context, campaign advertising would act, in Western democracies, as a partial substitute for a good press. To investigate this point, we use Cagé (2020) data on newspaper penetration at the department level in France. We split our departments depending on the median value of newspaper penetration, defined as the number of local daily newspapers sold normalized by the population. Online Appendix Table D.29 presents the results. We find a slightly higher effect of campaigns in districts where news penetration is low compared to districts where it is high. However, the difference is not statistically significant.

Deterring challenger Electors are not the only ones who can be influenced by campaign spending. Prospective and declared candidates also observe how much is spent in past and present elections. This could have a dissuasive effect: spending by a candidate - and in particular by the incumbent may indeed deter (high-quality) challengers from running (see e.g. Epstein and Zemsky, 1995). To investigate whether this is the case, we rely on our IV strategy for the French legislative elections, exploiting the ban on private donations from firms that was implemented in 1995. We investigate how the number of candidates and the spending of the other candidates changed between 1993 and 1997 depending on the change in the incumbent's spending, and we instrument this change by the amount of private donations from firms received by the incumbent in 1993.

Table 12 presents the results. The upper panel investigates the impact of a change in the incumbent's spending on the number of candidates running in the district (an observation is an electoral district in 1997). As expected given the results of Section 3.2.1. the first-stage estimates are negative and statistically significant: an increase in the amount of private donations from legal entities received by the incumbent in 1993 leads to a drop in the incumbent's spending in 1997 compared to 1993. The second-stage estimates show that an increase in the incumbent's spending does not seem to deter the entry of challengers; on the contrary, we find that an increase in the incumbent spending instrumented by the donations from legal entities received in 1993 leads to an increase in the number of candidates.

[Table 12 about here.]

Furthermore, if we investigate the impact of a change in the incumbent's spending on spending by her challengers (Table $12 \mathrm{~b}$, the observation is a candidate in 1997) rather than on the number of challengers standing for election, we find that this spending increases. In other words, there does not seem to be a deterring effect of private donations; if anything, we find the opposite. This finding is consistent with the results of Epstein and Zemsky (1995) who show that only in certain limited cases fundraising actually deters quality challengers from entering the race ${ }^{45}$

\footnotetext{
${ }^{44}$ Unfortunately, this information is not available at the district or candidate level in France, and is discontinued for recent years in the UK, making a systematic analysis of the efficiency of each different forms of spending impossible.

${ }^{45}$ This can also be related to Avis et al. (2017) who find that stricter campaign spending limits (and hence spending levels) actually increases political competition (such as the number of candidates). One way to rationalize this difference could be
} 
Finally, note that money in itself can convey information about a candidate's quality, especially when dealing with "impressionable" voters (Baron, 1994, Grossman and Helpman, 1996) 46 Private donations, in particular, can be seen as an effective instrument if donors are more likely to give money to high-quality candidates ${ }^{47}$ More generally, citizens may simply choose to vote for the candidate whom they know is receiving more donations, because they anticipate that she will win (a "bandwagon effect' 48 .

\subsection{Where money matters: decreasing marginal returns and external validity}

We have found that money matters in all of our settings, with striking similarities. An increase in candidates' spending (in absolute value or as a share of all candidates' spending) is associated with an improvement in her electoral results, across all years and political parties under consideration. In France and in the UK, the extreme-right parties stand out. Besides, in both countries, we find evidence of persuasion and mobilization mechanisms, through an informational channel of spending. All these parallels suggest that our results could be cautiously extended to other contexts that share similar features, in particular those with multiparty systems and relatively low spending levels due to campaign spending limits. This is, for instance, the case of Belgium, Brazil, Canada, Chile, Italy, New Zealand and South Korea.

Yet, although money matters both at French and British elections, it does not matter to the same extent. For instance, while the price of a vote we observe for the main right-wing party in the UK, the Conservatives, oscillates between $€ 4$ and $€ 5$, it is never lower than $€ 7$ for its French counterpart. For the main left-wing parties, the Labour party and Socialist party, the difference is even more pronounced: between $€ 4$ and $€ 8$ for the former, against $€ 13$ to $€ 21$ for the latter. While several factors could explain this, we argue that a key rationale is to be found in the scale of campaigns. As a matter of fact, we have seen that campaign spending displays decreasing returns to scale (online Appendix Table D.9]. Meanwhile, as shown in Table 1] total spending per candidate is on average 2 to 3 times larger in French legislative elections than in UK general elections (partly due to differences in regulation). The difference in the price of a vote in these two countries could thus come from the same relationship estimated at different baseline levels.

Extending that reasoning to countries such as the US, where campaign spending is relatively high

that, contrary to their setting, spending levels of our incumbents change but not the spending limits, leaving the threat for potential new entrants of existing candidates outspending them.

${ }^{46}$ The size of contributions has been proven to affect voters' perceptions of a candidate's ability as a fundraiser (Potters et al. 1997) or of the social benefits of her projects (Helsley and O'Sullivan. 1994). Lohmann (1993) develops a similar argument regarding the scale of mass political action.

${ }^{47}$ Note, however, that Snyder et al. (2010) show evidence that large contributions and contributions from individuals provide no informational benefit. Besides, unlike in the US, candidates for French and British local elections hardly communicate on the private donations they receive.

${ }^{48}$ There is a large literature on bandwagon effects, i.e. the fact that polls may lead to changes in preferences - see e.g. Simon (1954); Fleitas (1971); Gartner (1976); Duffy and Tavits (2008); Großer and Schram (2010). While in a recent study Gerber et al. (2020) find no causal evidence of bandwagon effects with respect to actual voting, Feigenbaum and Shelton (2013) show that fundraising is subject to bandwagoning in the context of US primary elections. 
(in part because there are no upper limit on how much candidates can spend), or Israel, it is possible to rationalize the ambiguous effects of electoral money that studies have found there (Levitt, 1994, BenBassat et al. 2015). At the 2016 US federal elections, the average spending of House incumbents and their direct challengers was indeed about $€ 1,010,00049$ in districts with around 710,000 registered voters, meaning a spending of roughly $€ 1.3$ per candidate per elector. This is 4 to 8 times more than in French legislative elections, and 16 to 20 times more than in the UK general elections. Campaign spending in the US could thus appear to have a limited impact simply because it has reached a level where the marginal returns of an additional dollar are close to zero.

\section{Conclusion}

Does money play in democratic elections? In this paper, we have investigated the impact of campaign spending on votes in legislative elections in France and the UK over three decades. We exploit panel data and changes in legislation to estimate the causal effect of spending on votes, and investigate whether the impact of campaigns varies across candidates, elections, districts and political parties. We find that, despite strict limitations on campaign spending, money plays an important role in shaping French and British parliaments.

What role does money play? Investigating the heterogeneity of the impact of campaign expenditures allows us to improve our understanding of the channels through which campaigns matter. We show that both mobilization and persuasion mechanisms are at play, most probably through information provision. We also document that the impact of expenditures varies depending on the political party in question. In particular, we show that spending by extreme-right candidates has much lower returns than spending by other parties. In recent years, far-right political parties have made major gains in elections throughout the West. Our results may shed some light on the mechanisms driving their electoral success.

We hope these results will benefit the public debate regarding the regulation of campaign finance, in particular the relevance of existing limits for contributions and/or spending (even if determining these levels is beyond the scope of this paper). We provide evidence that decreasing the amounts spent at elections, for instance through stricter spending limits, might, in fact, increase the importance of a marginal euro. That being said, it could nonetheless change the identity of candidates spending that euro, and of those contributing to their campaigns. We leave this question to future research.

\footnotetext{
49 $\$ 1,090,000$, own calculations
} 


\section{References}

Abadie, A. and Imbens, G. W. (2006). Large Sample Properties of Matching Estimators for Average Treatment Effects. Econometrica, 74(1):235-267.

Abadie, A. and Imbens, G. W. (2011). Bias-Corrected Matching Estimators for Average Treatment Effects. Journal of Business \& Economic Statistics, 29(1):1-11.

Abramowitz, A. I. (1988). Explaining senate election outcomes. American Political Science Review, 82(2):385-403.

Acharya, A., Grillo, E., Sugaya, T., and Turkel, E. (2019). Dynamic Campaign Spending. techreport. Adams, J. (2012). Causes and Electoral Consequences of Party Policy Shifts in Multiparty Elections: Theoretical Results and Empirical Evidence. Annual Review of Political Science, 15(1):401-419.

Adams, J., Merrill, S., Simas, E. N., and Stone, W. J. (2011). When Candidates Value Good Character: A Spatial Model with Applications to Congressional Elections. The Journal of Politics, 73(1):17-30.

Adams, J. and Somer-Topcu, Z. (2009). Moderate Now, Win Votes Later: The Electoral Consequences of Parties' Policy Shifts in 25 Postwar Democracies. The Journal of Politics, 71(2):678-692.

Adams, J. F., Merrill III, S., and Grofman, B. (2005). A Unified Theory of Party Competition: A Cross-National Analysis Integrating Spatial and Behavioral Factors. Cambridge University Press.

Altonji, J. G., Elder, T. E., and Taber, C. R. (2005). Selection on Observed and Unobserved Variables: Assessing the Effectiveness of Catholic Schools. Journal of Political Economy, 113(1):151-184.

Alvarez, R. M. and Nagler, J. (1998). When Politics and Models Collide: Estimating Models of Multiparty Elections. American Journal of Political Science, 42(1):55-96.

Ansolabehere, S., de Figueiredo, J. M., and Snyder, J. M. J. (2003). Why is There so Little Money in U.S. Politics? Journal of Economic Perspectives, 17(1):105-130.

Ansolabehere, S. and Snyder, J. M. (2000). Valence Politics and Equilibrium in Spatial Election Models. Public Choice, 103(3/4):327-336.

Aragones, E. and Palfrey, T. R. (2002). Mixed Equilibrium in a Downsian Model with a Favored Candidate. Journal of Economic Theory, 103(1):131-161.

Avis, E., Ferraz, C., Finan, F., and Varjão, C. (2017). Money and Politics: The Effects of Campaign Spending Limits on Political Competition and Incumbency Advantage. Working Paper 23508, National Bureau of Economic Research.

Baron, D. P. (1994). Electoral Competition with Informed and Uniformed Voters. The American Political Science Review, 88(1):33-47.

Ben-Bassat, A., Dahan, M., and Klor, E. F. (2015). Does Campaign Spending Affect Electoral Outcomes? Electoral Studies, 40(1):102-114.

Benoit, K. and Marsh, M. (2008). The Campaign Value of Incumbency: A New Solution to the Puzzle of Less Effective Incumbent Spending. American Journal of Political Science, 52(4):874-890.

Berry, S., Levinsohn, J., and Pakes, A. (1995). Automobile Prices in Market Equilibrium. Economet- 
rica, 63(4):841-890.

Bouton, L., Castanheira, M., and Drazen, A. (2018). A Theory of Small Campaign Contributions. NBER Working Papers 24413, National Bureau of Economic Research, Inc.

Bursztyn, L., Egorov, G., and Fiorin, S. (2020). From Extreme to Mainstream: The Erosion of Social Norms. American Economic Review, 110(11):3522-3548.

Cagé, J. (2018). Le prix de la démocratie. Fayard (English version: The Price of Democracy, Harvard University Press, 2020).

Cagé, J. (2020). Media Competition, Information Provision and Political Participation: Evidence from French Local Newspapers and Elections, 1944-2014. Journal of Public Economics, 185.

Cagé, J. and Dewitte, E. (2018). It Takes Money to Make MPs : New Evidence from 150 Years of British Campaign Spending. techreport.

Cagé, J. and Dewitte, E. (2020). The Rising Demand for Representation: Evidence from a 100 of British Political Selection. Working paper.

Carvalho, B. (2020). Campaign Spending on Local Elections: the More the Merrier? Working paper.

Coate, S. (2004a). Pareto-Improving Campaign Finance Policy. The American Economic Review, 94(3):628-655.

Coate, S. (2004b). Political Competition with Campaign Contributions and Informative Advertising. Journal of the European Economic Association, 2(5):772-804.

Cox, G. (1997). Making Votes Count. Cambridge University Press.

Da Silveira, B. S. and De Mello, J. M. P. (2011). Campaign Advertising and Election Outcomes: Quasinatural Experiment Evidence from Gubernatorial Elections in Brazil. The Review of Economic Studies, 78(2):590-612.

Dal Bo, E., Finan, F., Folke, O., Persson, T., and Rickne, J. (2019). Economic And Social Outsiders But Political Insiders: Sweden's Radical Right. Technical report.

de Figueiredo, J. M., Ji, C. H., and Kousser, T. (2011). Financing Direct Democracy: Revisiting the Research on Campaign Spending and Citizen Initiatives. Journal of Law, Economics, \& Organization, 27(3):485-514.

Dharmapala, D. and Palda, F. (2002). Are Campaign Contributions a Form of Speech? Evidence from Recent US House Elections. Public Choice, 112(1/2):81-114.

Downs, A. (1957). An Economic Theory of Democracy. Harper.

Duffy, J. and Tavits, M. (2008). Beliefs and Voting Decisions: A Test of the Pivotal Voter Model. American Journal of Political Science, 52(3):603-618.

Duverger, M. (1954). Political Parties. John Wiley \& Sons.

Enos, R. D., Fowler, A., and Vavreck, L. (2014). Increasing Inequality: The Effect of GOTV Mobilization on the Composition of the Electorate. The Journal of Politics, 76(1):273-288.

Epstein, D. and Zemsky, P. (1995). Money Talks: Deterring Quality Challengers in Congressional Elections. The American Political Science Review, 89(2):295-308. 
Erikson, R. S. and Palfrey, T. R. (1998). Campaign Spending and Incumbency: An Alternative Simultaneous Equations Approach. The Journal of Politics, 60(2):355-373.

Feigenbaum, J. J. and Shelton, C. A. (2013). The Vicious Cycle: Fundraising and Perceived Viability in US Presidential Primaries. Quarterly Journal of Political Science, 8(1):1-40.

Fleitas, D. W. (1971). Bandwagon and Underdog Effects in Minimal-Information Elections. American Political Science Review, 65(2):434-438.

Foucault, M. and François, A. (2005). Le rendement des dépenses électorales en France. Le cas des élections législatives de 1997. Revue économique, 56(5):1125-1143.

François, A., Visser, M., and Wilner, L. (2016). Using Political Financing Reforms to Measure Campaign Spending Effects on Electoral Outcomes. CESifo Working Paper 6232.

Gandhi, A., Iorio, D., and Urban, C. (2015). Negative Advertising and Political Competition. The Journal of Law, Economics, and Organization, 32(3):433-477.

Gartner, M. (1976). Endogenous Bandwagon and Underdog Effects in a Rational Choice Model. Public Choice, 25:83-89.

Gerber, A. (1998). Estimating the Effect of Campaign Spending on Senate Election Outcomes Using Instrumental Variables. The American Political Science Review, 92(2):401-411.

Gerber, A., Hoffman, M., Morgan, J., and Raymond, C. (2020). One in a Million: Field Experiments on Perceived Closeness of the Election and Voter Turnout. American Economic Journal: Applied Economics, 12(3):287-325.

Gerber, A. S. (2004). Does Campaign Spending Work? American Behavioral Scientist, 47(5):541-574.

Gerber, A. S. and Green, D. P. (2000). The Effects of Canvassing, Telephone Calls, and Direct Mail on Voter Turnout: A Field Experiment. The American Political Science Review, 94(3):pp. 653-663.

Green, D. P. and Krasno, J. S. (1988). Salvation for the Spendthrift Incumbent: Reestimating the Effects of Campaign Spending in House Elections. American Journal of Political Science, 32(4):884-907.

Groseclose, T. (2001). A Model of Candidate Location When One Candidate Has a Valence Advantage. American Journal of Political Science, 45(4):862-886.

Großer, J. and Schram, A. (2010). Public Opinion Polls, Voter Turnout, and Welfare: An Experimental Study. American Journal of Political Science, 54(3):700-717.

Grossman, G. M. and Helpman, E. (1996). Electoral Competition and Special Interest Politics. The Review of Economic Studies, 63(2):265-286.

Grossman, G. M. and Helpman, E. (2001). Special Interest Politics. MIT Press.

Gunlicks, A. B. (1993). Campaign and Party Finance in North America and Western Europe. Westview Press.

Guriev, S. and Papaioannou, E. (2020). The Political Economy of Populism. Technical report.

Harteveld, E., Dahlberg, S., Kokkonen, A., and Van Der Brug, W. (2019a). Gender Differences in Vote Choice: Social Cues and Social Harmony as Heuristics. British Journal of Political Science, 49(3):1141-1161. 
Harteveld, E., Dahlberg, S., Kokkonen, A., and van der Brug, W. (2019b). Social Stigma and Support for the Populist Radical Right: An Experimental Study. Scandinavian Political Studies, 42(3-4):296-307.

Helsley, R. W. and O'Sullivan, A. (1994). Altruistic voting and campaign contributions. Journal of Public Economics, 55(1):107-119.

Herrera, H., Levine, D. K., and Martinelli, C. (2008). Policy platforms, campaign spending and voter participation. Journal of Public Economics, 92(3-4):501-513.

Herriot, J. G. and Reinsch, C. H. (1973). Algorithm 472: procedures for natural spline interpolation [E1]. Commun. ACM, 16(12):763-768.

Honaker, J., Katz, J. N., and King, G. (2002). A Fast, Easy, and Efficient Estimator for Multiparty Electoral Data. Political Analysis, 10(1):84-100.

Jacobson, G. C. (1978). The Effects of Campaign Spending in Congressional Elections. The American Political Science Review, 72(2):469-491.

Jacobson, G. C. (1980). Money in Congressional Elections. Yale University Press.

Jacobson, G. C. (1985). Money and Votes Reconsidered: Congressional Elections, 1972-1982. Public Choice, 47(1):7-62.

Jacobson, G. C. (1990). The Effects of Campaign Spending in House Elections: New Evidence for Old Arguments. American Journal of Political Science, 34(2):334-362.

Jacobson, G. C. (2006). Campaign spending effects in U.S. Senate elections: Evidence from the National Annenberg Election Survey. Electoral Studies, 25(2):195-226.

Jacobson, G. C. (2015). How Do Campaigns Matter? Annual Review of Political Science, 18(1):31-47.

Johnston, R. and Pattie, C. (2014). Money and Electoral Politics. Local Parties and Funding in General Elections. Policy Press.

Kalla, J. L. and Broockman, D. E. (2018). The Minimal Persuasive Effects of Campaign Contact in General Elections: Evidence from 49 Field Experiments. American Political Science Review, 112(1):148-166.

Katz, J. N. and King, G. (1999). A Statistical Model for Multiparty Electoral Data. The American Political Science Review, 93(1):15-32.

Kestilä-Kekkonen, E. and Söderlund, P. (2014). Party, leader or candidate? dissecting the right-wing populist vote in Finland. European Political Science Review, 6(4):641-662.

King, G., Honaker, J., Joseph, A., and Scheve, K. (2001). Analyzing Incomplete Political Science Data: An Alternative Algorithm for Multiple Imputation. The American Political Science Review, 95(1):49-69.

Larcinese, V. and Miner, L. (2018). Was Obama Elected by the Internet? Broadband Diffusion and Voters' Behavior in US Presidential Elections. Technical report.

Larreguy, H. A., Marshall, J., and Snyder, J. J. M. (2018). Leveling the playing field: How campaign advertising can help non-dominant parties. Journal of the European Economic Association, 
16(6):1812-1849.

Le Bras, H. (2015). Le pari du FN. Angles et Reliefs. Autrement.

Le Pennec-Caldichoury, C. (2019). Strategic Campaign Communication: Evidence from 30,000 Candidate Manifestos. Working paper.

Lenz, G. S. (2009). Learning and Opinion Change, Not Priming: Reconsidering the Priming Hypothesis. American Journal of Political Science, 53(4):821-837.

Levitt, S. D. (1994). Using Repeat Challengers to Estimate the Effect of Campaign Spending on Election Outcomes in the U.S. House. Journal of Political Economy, 102(4):777-798.

Lohmann, S. (1993). A Signaling Model of Informative and Manipulative Political Action. The American Political Science Review, 87(2):319-333.

Nassmacher, K.-H. (2009). The Funding of Party Competition: Political Finance in 25 Democracies. Nomos.

Nevo, A. (2000). A Practitioner's Guide to Estimation of Random-Coefficients Logit Models of Demand. Journal of economics \& management strategy, 9(4):513-548.

Oster, E. (2013). Unobservable Selection and Coefficient Stability: Theory and Validation. Mimeo, Chicago Booth School of Business.

Palda, F. and Palda, K. (1998). The Impact of Campaign Expenditures on Political Competition in the French Legislative Elections of 1993. Public Choice, 94(1/2):157-174.

Panagopoulos, C. (2016). All about that base: Changing campaign strategies in U.S. Presidential elections. Party Politics, 22(2):179-190.

Panagopoulos, C. and Green, D. P. (2008). Field Experiments Testing the Impact of Radio on Electoral Advertisements Competition. American Journal of Political Science, 52(1):156-168.

Peterson, D. A. M. (2009). Campaign Learning and Vote Determinants. American Journal of Political Science, 53(2):445-460.

Piketty, T. (2018). Brahmin Left vs Merchant Right: Rising Inequality \& the Changing Structure of Political Conflict. Technical report.

Pons, V. (2018). Will a five-minute discussion change your mind? A countrywide experiment on voter choice in France. American Economic Review, 108(6):1322-1363.

Potters, J., Sloof, R., and van Winden, F. (1997). Campaign expenditures, contributions and direct endorsements: The strategic use of information and money to influence voter behavior. European Journal of Political Economy, 13(1):1-31.

Prat, A. (2002a). Campaign Advertising and Voter Welfare. The Review of Economic Studies, 69(4):999-1017.

Prat, A. (2002b). Campaign Spending with Office-Seeking Politicians, Rational Voters, and Multiple Lobbies. Journal of Economic Theory, 103(1):162-189.

Rekkas, M. (2007). The Impact of Campaign Spending on Votes in Multiparty Elections. The Review of Economics and Statistics, 89(3):573-585. 
Scarrow, S. (2007). Political Finance in Comparative Perspective. Annual Review of Political Science, 10:193-210.

Schultz, C. (2007). Strategic Campaigns and Redistributive Politics. The Economic Journal, 117(522):936-963.

Simon, H. A. (1954). Bandwagon and Underdog Effects and the Possibility of Election Predictions. The Public Opinion Quarterly, 18(3):245-253.

Snyder, J. M., Prat, A., and Puglisi, R. (2010). Is Private Campaign Finance a Good Thing? Estimates of the Potential Information Benefits. Quarterly Journal of Political Science, 5(3):291-318.

Speck, B. (2013). Money in Politics: Sound Political Competition and Trust in Government. Oecd background paper.

Spenkuch, J. L. and Toniatti, D. (2018). Political Advertising and Election Results. The Quarterly Journal of Economics, 133(4):1981-2036.

Stock, J. H. and Yogo, M. (2005). Testing for Weak Instruments in Linear IV Regression. In Identification and Inference for Econometric Models: Essays in Honor of Thomas Rothenberg, pages pp. 80-108. Cambridge: Cambridge University Press.

Stockemer, D., Lentz, T., and Mayer, D. (2018). Individual Predictors of the Radical Right-Wing Vote in Europe: A Meta-Analysis of Articles in Peer-Reviewed Journals (1995-2016). Government and Opposition, 53(3):569-593.

Stone, W. J. and Simas, E. N. (2010). Candidate Valence and Ideological Positions in U.S. House Elections. American Journal of Political Science, 54(2):371-388.

Tomz, M., Tucker, J. A., and Wittenberg, J. (2002). An Easy and Accurate Regression Model for Multiparty Electoral Data. Political Analysis, 10(1):66-83.

Vanberg, C. (2008). "One Man, One Dollar"? Campaign contribution limits, equal influence, and political communication. Journal of Public Economics, 92(3-4):514-531.

Williams, L. K. and Whitten, G. D. (2015). Don't Stand So Close to Me: Spatial Contagion Effects and Party Competition. American Journal of Political Science, 59(2):309-325.

Zaller, J. R. (1992). The Nature and Origins of Mass Opinion. Cambridge University Press. 

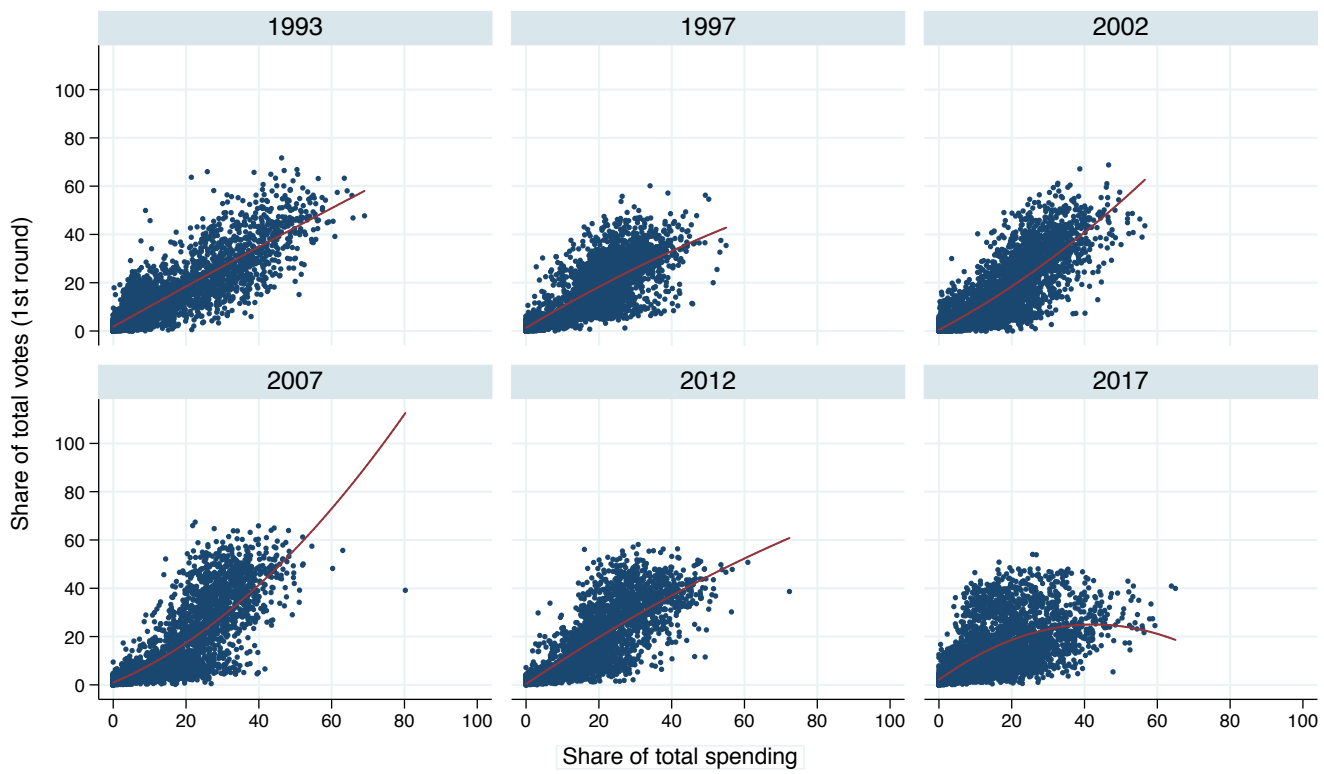

(a) French Legislative Elections
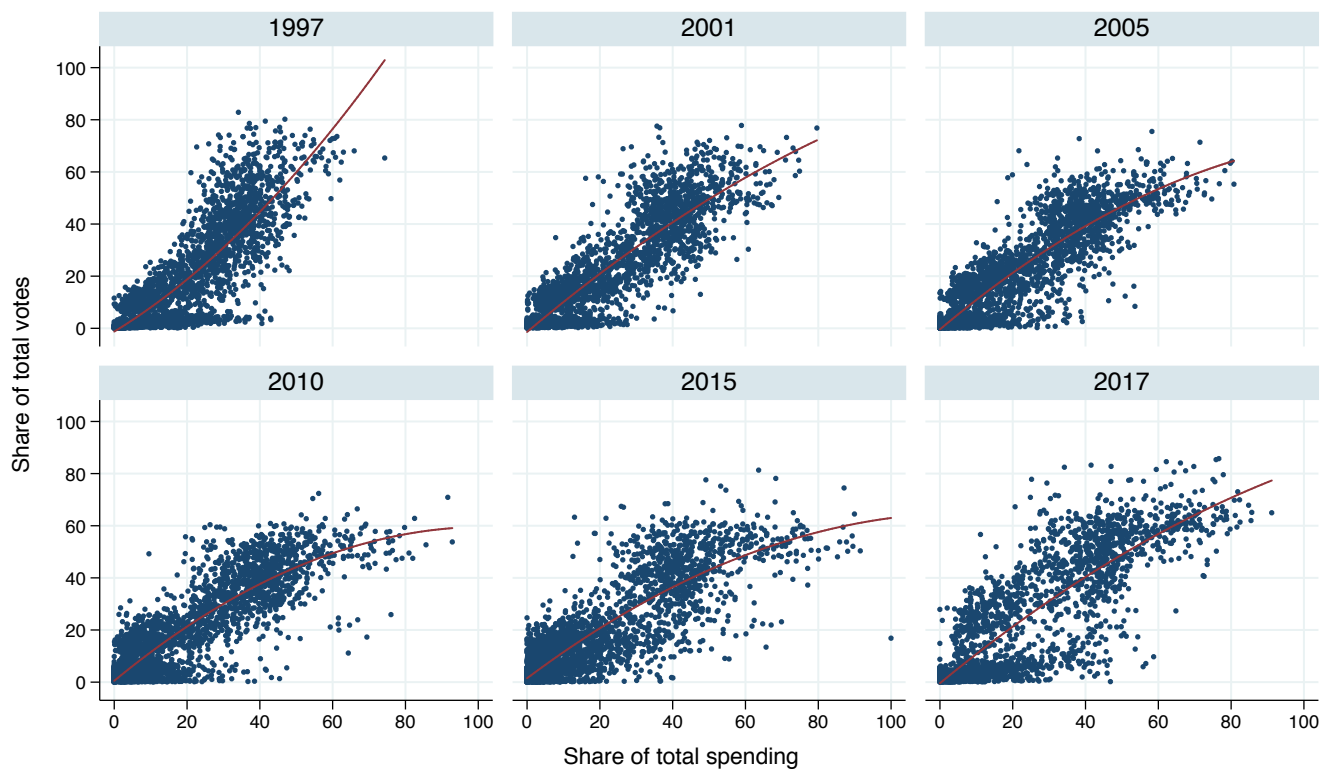

(b) UK General Elections

Notes: The figure plots the relationship between the proportions of total spending and total (first round) vote share received by the candidates. An observation is a candidate-electoral district. The upper figure 1a shows this relationship for the French legislative elections. The bottom figure $1 \mathrm{~b}$ shows this relationship for the UK General Elections.

Figure 1: Relationship between candidates' shares of district total spending and share of total votes 


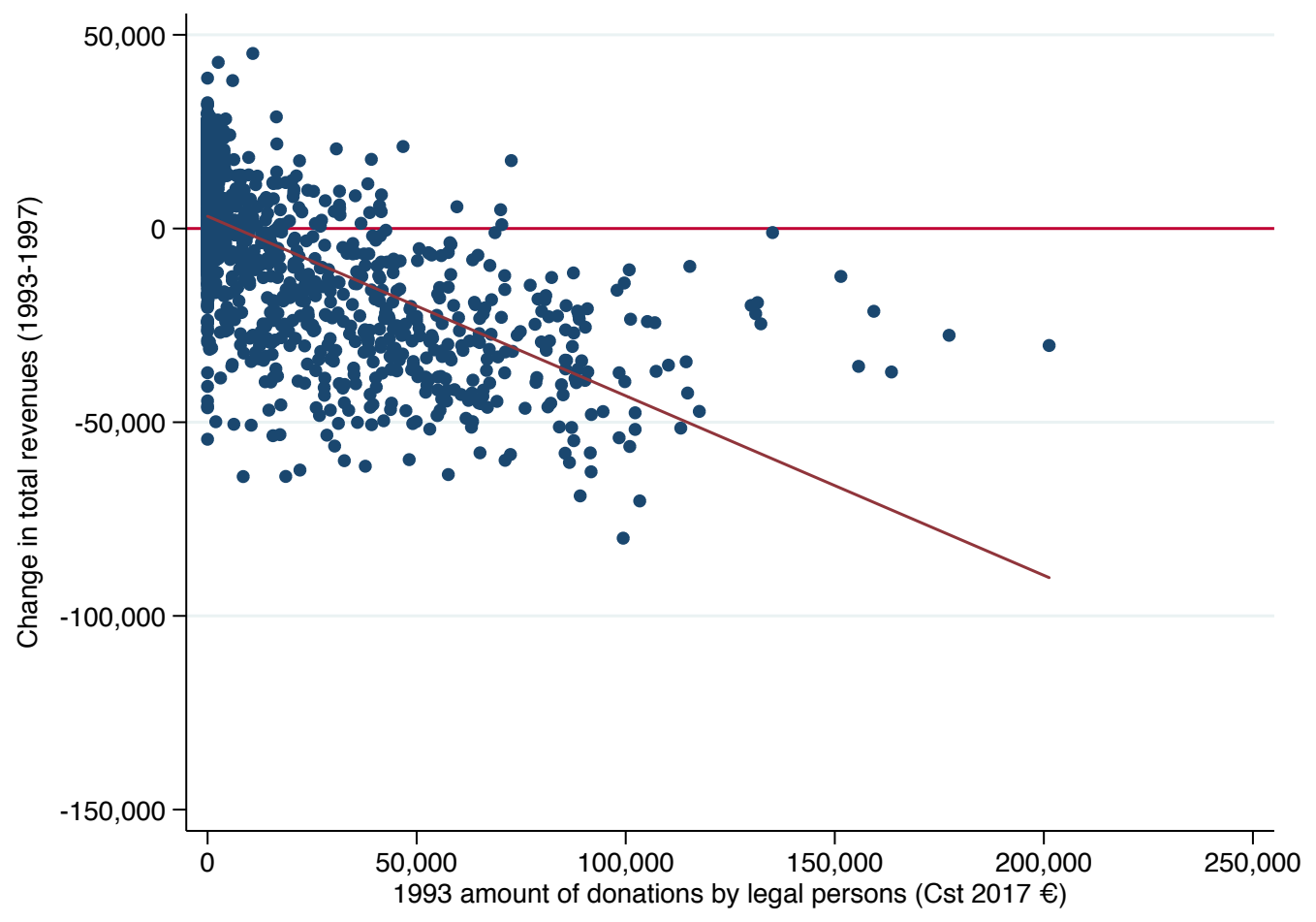

Notes: The figure plots the correlation between the change in total revenues between 1993 and 1997 and the donations from legal entities received in 1993. An observation is a candidate running both in 1993 and 1997 in the French legislative elections.

Figure 2: Change in total revenues between 1993 and 1997 depending on the donations from legal entities received in 1993 - French legislative elections 


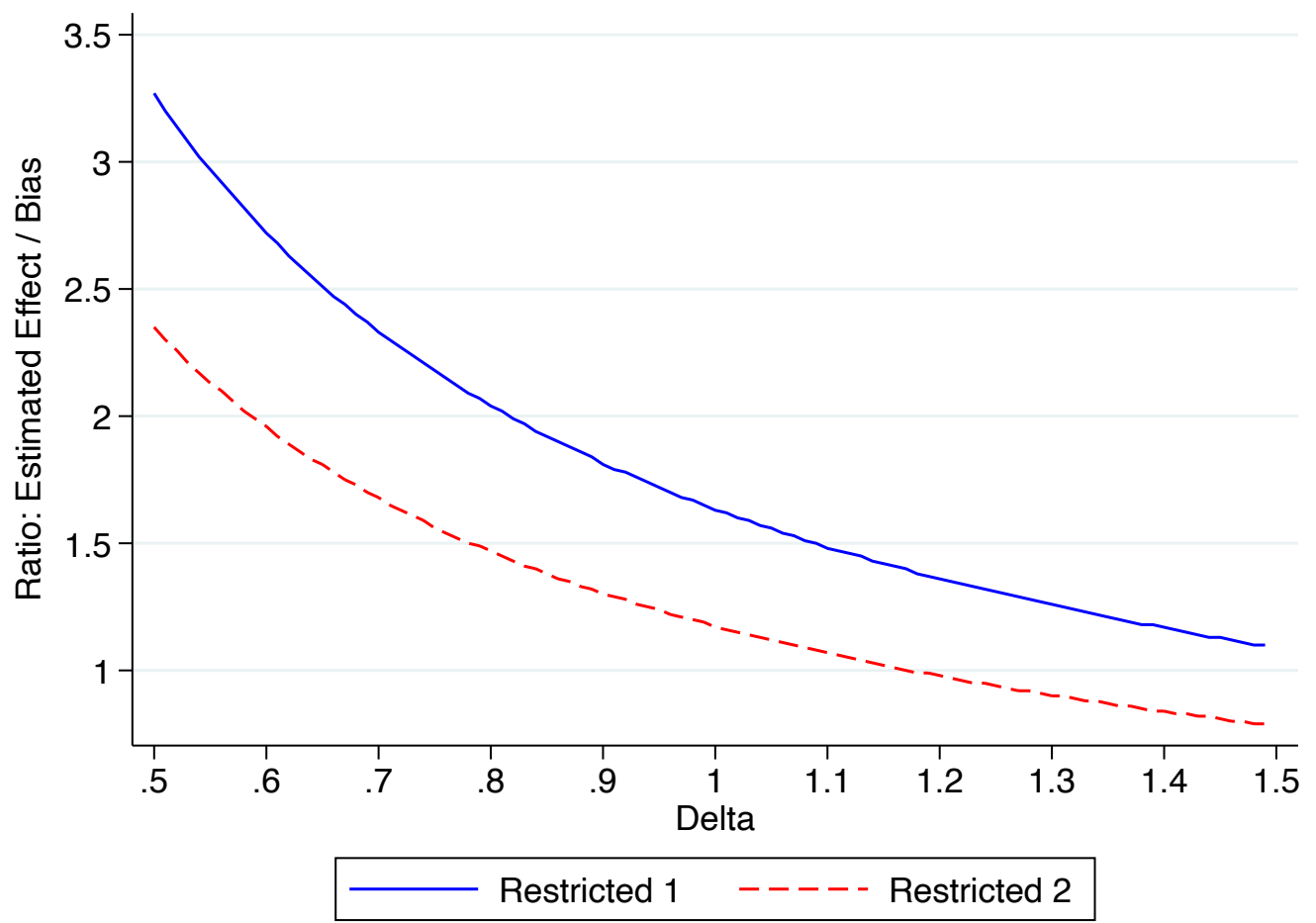

Notes: The figure plots the ratio of the estimated correlation between campaign spending and votes (as given in the Column (5) of Table 3a) over the bias $B(\delta)$ due to unobservables (see Oster (2013)) using two different sets of restricted controls $M$. The first set ("Restricted 1") only includes candidates and party-year fixed effects. The second set ("Restricted 2") includes candidates and party-year fixed effects, the number of candidates running, the margin at the last election, the total spending per elector in the district, and the number of registered voters. The value $R_{\max }=0.3$ is used to compute $B(\delta)$.

Figure 3: Magnitude of the effect relative to the bias from unobservables, for different values of $\delta$ French legislative elections 


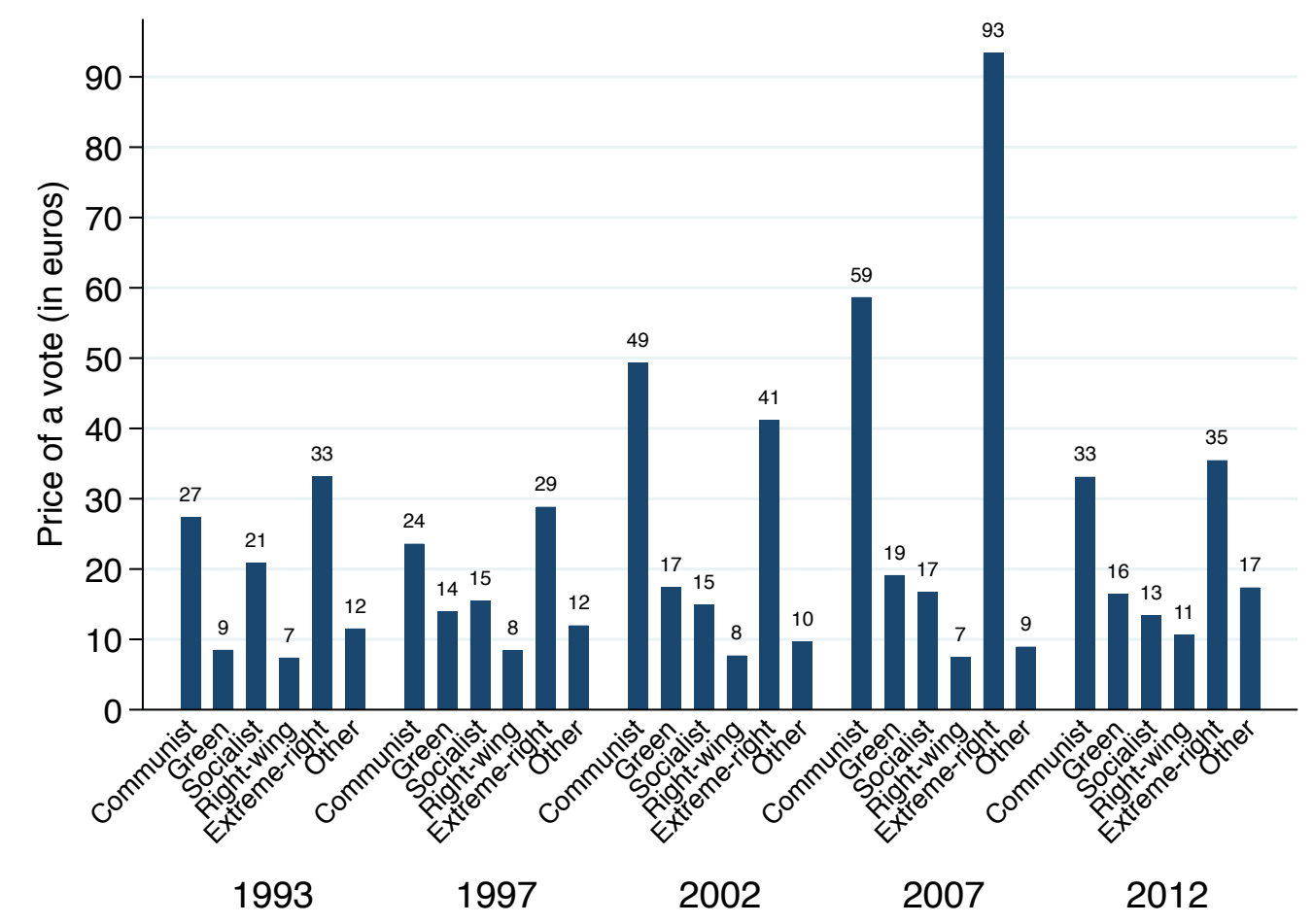

Notes: The figure plots the average price of a vote, depending on the time period and on the political party. These prices are obtained performing the counterfactual estimations that are described in Section 4.2

Figure 4: The price of a vote, depending on the election and on the political party - French legislative elections 


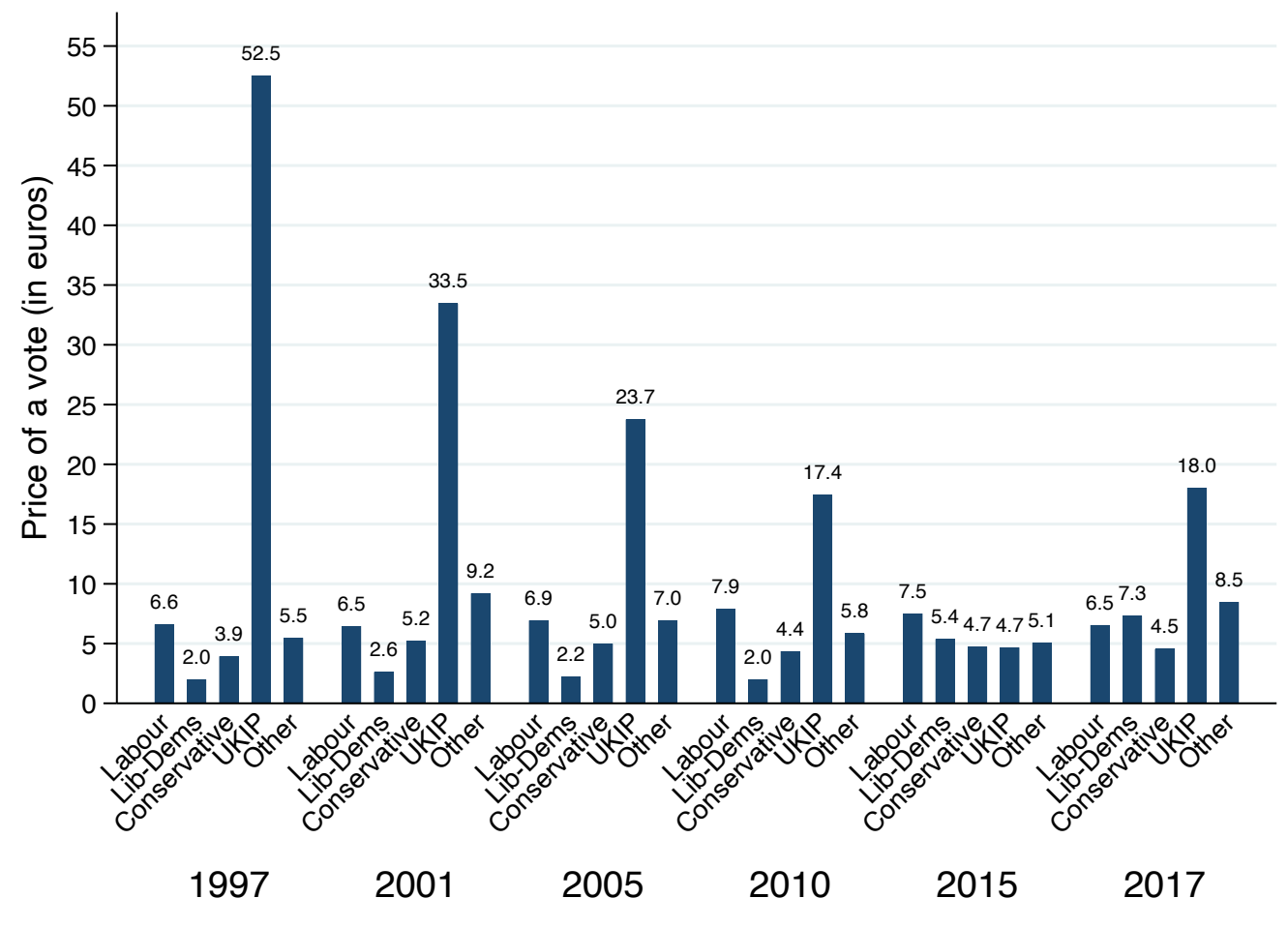

Notes: The figure plots the average price of a vote, depending on the time period and on the political party. These prices are obtained performing the counterfactual estimations that are described in Section 4.2

Figure 5: The price of a vote, depending on the election and on the political party - UK general election 
Table 1: Summary statistics: campaign spending by elections, depending on the years

(a) French legislative elections

\begin{tabular}{lcccccc}
\hline \hline & \multicolumn{5}{c}{ Spending (cst 2017 €) } \\
\cline { 2 - 7 } & Mean & Median & sd & Min & Max & N \\
\hline Total spending per candidate & & & & & & \\
1993 & 20,397 & 10,503 & 25,369 & 0 & 160,756 & 5,115 \\
1997 & 14,607 & 2,257 & 18,647 & 0 & 72,122 & 5,975 \\
2002 & 10,742 & 1,351 & 16,361 & 0 & 77,565 & 7,928 \\
2007 & 10,708 & 607 & 16,180 & 0 & 72,495 & 7,173 \\
2012 & 17,891 & 16,958 & 16,793 & 0 & 69,823 & 3,939 \\
2017 & 12,708 & 7,108 & 14,256 & 0 & 68,738 & 5,057 \\
All years & 13,878 & 4,268 & 18,427 & 0 & 160,756 & 35,187 \\
Total spending per elector & & & & & & \\
1993 & 2.84 & 2.68 & 1.14 & 0.46 & 8.58 & 555 \\
1997 & 2.37 & 2.27 & 0.72 & 0.96 & 5.98 & 555 \\
2002 & 2.26 & 2.06 & 0.87 & 0.77 & 7.08 & 555 \\
2007 & 1.89 & 1.76 & 0.62 & 0.60 & 5.07 & 555 \\
2012 & 1.67 & 1.59 & 0.51 & 0.44 & 4.41 & 539 \\
2017 & 1.49 & 1.40 & 0.51 & 0.49 & 3.79 & 539 \\
All years & 2.09 & 1.90 & 0.89 & 0.44 & 8.58 & 3,298 \\
Per candidate \& per elector & & & & & & \\
1993 & 0.31 & 0.15 & 0.39 & 0.00 & 3.84 & 5,115 \\
1997 & 0.22 & 0.03 & 0.29 & 0.00 & 1.79 & 5,975 \\
2002 & 0.16 & 0.02 & 0.25 & 0.00 & 1.51 & 7,928 \\
2007 & 0.15 & 0.01 & 0.23 & 0.00 & 1.42 & 7,173 \\
2012 & 0.23 & 0.20 & 0.22 & 0.00 & 1.26 & 3,939 \\
2017 & 0.16 & 0.09 & 0.18 & 0.00 & 1.27 & 5,057 \\
All years & 0.20 & 0.06 & 0.27 & 0.00 & 3.84 & 35,187 \\
\hline \hline
\end{tabular}

(b) UK general elections

\begin{tabular}{|c|c|c|c|c|c|c|}
\hline & \multicolumn{6}{|c|}{ Spending (cst $2017 €$ ) } \\
\hline & Mean & Median & $\mathrm{sd}$ & Min & $\operatorname{Max}$ & $\mathrm{N}$ \\
\hline \multicolumn{7}{|c|}{ Total spending per candidate } \\
\hline 1997 & 5,883 & 4,749 & 4,637 & 0 & 16,920 & 3,128 \\
\hline 2001 & 5,709 & 3,761 & 4,954 & 0 & 23,185 & 2,782 \\
\hline 2005 & 5,671 & 3,316 & 5,256 & 0 & 32,598 & 3,018 \\
\hline 2010 & 4,454 & 1,940 & 4,788 & 0 & 22,265 & 3,413 \\
\hline 2015 & 4,600 & 2,058 & 5,126 & 0 & 24,384 & 3,125 \\
\hline 2017 & 4,797 & 2,238 & 5,071 & 0 & 23,114 & 2,878 \\
\hline All years & 5,167 & 2,919 & 5,005 & 0 & 32,598 & 18,344 \\
\hline \multicolumn{7}{|c|}{ Total spending per elector } \\
\hline 1997 & 0.47 & 0.47 & 0.14 & 0.18 & 0.98 & 569 \\
\hline 2001 & 0.41 & 0.40 & 0.12 & 0.12 & 1.00 & 569 \\
\hline 2005 & 0.44 & 0.43 & 0.15 & 0.11 & 1.52 & 569 \\
\hline 2010 & 0.38 & 0.38 & 0.13 & 0.05 & 0.93 & 573 \\
\hline 2015 & 0.36 & 0.35 & 0.15 & 0.00 & 0.98 & 560 \\
\hline 2017 & 0.34 & 0.33 & 0.12 & 0.09 & 0.93 & 573 \\
\hline All years & 0.40 & 0.40 & 0.14 & 0.00 & 1.52 & 3,413 \\
\hline \multicolumn{7}{|c|}{ Per candidate $\&$ per elector } \\
\hline 1997 & 0.09 & 0.07 & 0.07 & 0.00 & 0.31 & 3,128 \\
\hline 2001 & 0.08 & 0.05 & 0.07 & 0.00 & 0.33 & 2,782 \\
\hline 2005 & 0.08 & 0.05 & 0.08 & 0.00 & 0.47 & 3,018 \\
\hline 2010 & 0.06 & 0.03 & 0.07 & 0.00 & 0.30 & 3,413 \\
\hline 2015 & 0.06 & 0.03 & 0.07 & 0.00 & 0.35 & 3,125 \\
\hline 2017 & 0.07 & 0.03 & 0.07 & 0.00 & 0.32 & 2,878 \\
\hline All years & 0.07 & 0.04 & 0.07 & 0.00 & 0.47 & 18,344 \\
\hline
\end{tabular}

Notes: The table presents summary statistics on spending by candidates running in French legislative and UK general elections, for each elections-year. For the "total spending per candidate" and the total spending "per candidate \& per voter" variables, an observation is a candidate-election. For the "total spending per voter" variable, an observation is an electoral district-election. 
Table 2: Summary statistics: campaign spending by elections, depending on the political parties

(a) French legislative elections

\begin{tabular}{lcccccc}
\hline \hline & \multicolumn{5}{c}{ Spending (cst 2017 €) } \\
\cline { 2 - 7 } & Mean & Median & sd & Min & Max & N \\
\hline Total spending per candidate & & & & & & \\
Communist Party & 15,381 & 10,914 & 14,577 & 0 & 97,962 & 3,027 \\
Green Party & 6,430 & 2,430 & 9,387 & 0 & 70,420 & 2,586 \\
Socialist Party & 35,497 & 33,721 & 16,591 & 0 & 128,015 & 2,960 \\
Right-wing Party & 44,166 & 43,120 & 18,914 & 0 & 160,756 & 3,180 \\
Extreme-right Party & 20,426 & 19,474 & 10,703 & 0 & 62,643 & 3,246 \\
Other & 7,444 & 1,035 & 13,639 & 0 & 104,730 & 9,180 \\
Per candidate \& per elector & & & & & & \\
Communist Party & 0.22 & 0.15 & 0.24 & 0 & 2.03 & 3,027 \\
Green Party & 0.09 & 0.03 & 0.14 & 0 & 1.12 & 2,586 \\
Socialist Party & 0.50 & 0.45 & 0.27 & 0 & 2.12 & 2,960 \\
Right-wing Party & 0.62 & 0.58 & 0.32 & 0 & 3.84 & 3,180 \\
Extreme-right Party & 0.28 & 0.26 & 0.16 & 0 & 1.08 & 3,246 \\
Other & 0.10 & 0.01 & 0.20 & 0 & 2.46 & 9,180 \\
As share of the spending limit & & & & & & \\
Communist Party & 21 & 14 & 20 & 0 & 100 & 3,027 \\
Green Party & 9 & 3 & 13 & 0 & 99 & 2,586 \\
Socialist Party & 48 & 48 & 20 & 0 & 100 & 2,960 \\
Right-wing Party & 60 & 62 & 22 & 0 & 100 & 3,180 \\
Extreme-right Party & 29 & 28 & 16 & 0 & 100 & 3,246 \\
Other & 10 & 1 & 18 & 0 & 100 & 9,180 \\
\hline \hline
\end{tabular}

(b) UK general elections

\begin{tabular}{lcccccc}
\hline \hline & \multicolumn{6}{c}{ Spending (cst 2017 €) } \\
\cline { 2 - 7 } & Mean & Median & sd & Min & Max & N \\
\hline Total spending per candidate & & & & & & \\
Labour Party & 8,424 & 8,761 & 4,239 & 0 & 21,560 & 3,378 \\
Liberal Democrats & 4,848 & 2,828 & 4,603 & 0 & 18,413 & 3,338 \\
Conservative Party & 10,097 & 11,482 & 4,364 & 0 & 32,598 & 3,382 \\
UKIP & 2,135 & 1,274 & 2,772 & 0 & 27,284 & 2,407 \\
Other & 1,859 & 901 & 2,644 & 0 & 19,678 & 5,839 \\
Per candidate \& per elector & & & & & & \\
Labour Party & 0.12 & 0.13 & 0.06 & 0 & 0.29 & 3,378 \\
Liberal Democrats & 0.07 & 0.04 & 0.06 & 0 & 0.30 & 3,338 \\
Conservative Party & 0.14 & 0.16 & 0.06 & 0 & 0.47 & 3,382 \\
UKIP & 0.03 & 0.02 & 0.04 & 0 & 0.40 & 2,407 \\
Other & 0.03 & 0.01 & 0.04 & 0 & 0.33 & 5,839 \\
As share of the spending limit & & & & & & \\
Labour Party & 58 & 62 & 30 & 0 & 145 & 3,378 \\
Liberal Democrats & 32 & 19 & 31 & 0 & 107 & 3,338 \\
Conservative Party & 67 & 77 & 28 & 0 & 112 & 3,382 \\
UKIP & 13 & 8 & 17 & 0 & 101 & 2,407 \\
Other & 13 & 6 & 18 & 0 & 111 & 5,839 \\
\hline \hline
\end{tabular}

Notes: The table presents summary statistics on spending by candidates running in French legislative elections and UK general elections, depending on the political parties. An observation is a candidate-election. As seen at the bottom of panel $2 b$ there are (rare) cases where candidates at the UK general elections spend more than the legal limit. While few of these breaches have been the target of Electoral Petitions, the last election to have been declared void because of limit excess was in 1923. 
Table 3: The average effect of campaign spending on votes: Baseline estimations

(a) French legislative elections

\begin{tabular}{|c|c|c|c|c|c|}
\hline & \multicolumn{3}{|c|}{ All candidates } & \multicolumn{2}{|c|}{ Multiple times candidates } \\
\hline & (1) & $(2)$ & (3) & (4) & (5) \\
\hline Share of district total spending & $\begin{array}{c}0.064^{* * *} \\
(0.001)\end{array}$ & $\begin{array}{c}0.062^{* * *} \\
(0.001)\end{array}$ & $\begin{array}{c}0.059^{* * *} \\
(0.001)\end{array}$ & $\begin{array}{c}0.050^{* * *} \\
(0.001)\end{array}$ & $\begin{array}{c}0.019^{* * *} \\
(0.001)\end{array}$ \\
\hline District FE & $\checkmark$ & $\checkmark$ & $\checkmark$ & $\checkmark$ & \\
\hline Election-Party FE & $\checkmark$ & $\checkmark$ & $\checkmark$ & $\checkmark$ & $\checkmark$ \\
\hline Candidate FE & & & & & $\checkmark$ \\
\hline District-level controls & & $\checkmark$ & $\checkmark$ & $\checkmark$ & $\checkmark$ \\
\hline Candidate-level controls & & & $\checkmark$ & $\checkmark$ & $\checkmark$ \\
\hline R-sq (within) & 0.29 & 0.30 & 0.31 & 0.40 & 0.14 \\
\hline Observations & 34,824 & 32,612 & 32,602 & 12,882 & 12,882 \\
\hline Cluster (district) & 572 & 547 & 547 & 547 & 547 \\
\hline Mean DepVar & -2.9 & -2.8 & -2.8 & -2.2 & -2.2 \\
\hline Sd DepVar & 1.6 & 1.5 & 1.5 & 1.5 & 1.5 \\
\hline
\end{tabular}

(b) UK general elections

\begin{tabular}{lcccccc}
\hline \hline & \multicolumn{3}{c}{ All candidates } & & \multicolumn{2}{c}{ Multiple times candidates } \\
\cline { 2 - 3 } \cline { 7 - 7 } & $(1)$ & $(2)$ & $(3)$ & & $(4)$ & $(5)$ \\
\hline Share of district total spending & $0.031^{* * *}$ & $0.031^{* * *}$ & $0.028^{* * *}$ & & $0.023^{* * *}$ & $0.014^{* * *}$ \\
& $(0.001)$ & $(0.001)$ & $(0.001)$ & & $(0.001)$ & $(0.001)$ \\
\hline District FE & $\checkmark$ & $\checkmark$ & $\checkmark$ & $\checkmark$ & \\
Election*Party FE & $\checkmark$ & $\checkmark$ & $\checkmark$ & $\checkmark$ & $\checkmark$ \\
Candidate FE & & & & & $\checkmark$ \\
Constit-level controls & & $\checkmark$ & $\checkmark$ & & $\checkmark$ \\
Candidate-level controls & & & $\checkmark$ & & $\checkmark$ \\
R-sq (within) & 0.34 & 0.35 & 0.37 & & 0.39 & 0.27 \\
Observations & 18,351 & 18,351 & 18,351 & 9,476 & 9,476 \\
Cluster (district) & 583 & 583 & 583 & & 583 & 583 \\
Mean DepVar & -2.0 & -2.0 & -2.0 & & -1.4 & -1.4 \\
Sd DepVar & 1.7 & 1.7 & 1.7 & & 1.5 & 1.5 \\
\hline \hline
\end{tabular}

Notes: $* \mathrm{p}<0.10, * * \mathrm{p}<0.05, * * * \mathrm{p}<0.01$. The models are estimated using OLS estimates. An observation is a candidate-election. The dependent variable is the logarithm of the ratio of the number of votes obtained by a candidate over abstention. All the estimations include party interacted with election fixed effects. The model in Columns (1) to (4) also includes district fixed effects, while the model in Column (5) also includes candidate fixed effects. Standard errors are clustered at the district level. The time-varying district-level controls include the share of the population by age group, occupation and degree, the unemployment rate, the share of the employees who are part of the top $1 \%$ of the income distribution, the total spending at the district level, the number of candidates running, the margin at last election between the first and second largest vote counts, and the number of registered voters. The candidate-level controls include her gender (except in Column (5)), indicator variables for the candidates' political mandates, and an indicator variable equal to one if the candidate is the incumbent and to zero otherwise. Coefficients for the controls are not reported for the sake of space. Variables are described in more detail in the text. 
Table 4: Summary statistics: donations from legal entities - French legislative elections

(a) All 1993 candidates

\begin{tabular}{lcccccc}
\hline \hline & \multicolumn{5}{c}{ Legislative elections (1993) } \\
\cline { 2 - 7 } & Mean & Median & P95 & P99 & Max & Obs \\
\hline Donations from legal entities & 8,079 & 0 & 55,018 & 96,946 & 330,208 & 5,115 \\
Per registered voter & 0.12 & 0.00 & 0.79 & 1.50 & 6.28 & 5,115 \\
As a \% of total revenues & 12.7 & 0.0 & 70.8 & 91.8 & 1135 & 5,115 \\
As a \% of total private entities & 22.5 & 0.0 & 96.6 & 100 & 100 & 5,115 \\
\hline \hline
\end{tabular}

(b) Candidates running both in 1993 and 1997

\begin{tabular}{lcccccc}
\hline \hline & \multicolumn{5}{c}{ Legislative elections (1993) } \\
\cline { 2 - 7 } & Mean & Median & P95 & P99 & Max & Obs \\
\hline Donations from legal entities & 14,669 & 0 & 75,943 & 113,186 & 201,274 & 1,517 \\
Per registered voter & 0.22 & 0.00 & 1.11 & 1.71 & 3.46 & 1,517 \\
As a \% of total revenues & 18.0 & 0.0 & 74.7 & 89.9 & 98.4 & 1,517 \\
As a \% of total private entities & 32.1 & 0.0 & 97.1 & 100 & 100 & 1,517 \\
\hline \hline
\end{tabular}

Notes: The table gives summary statistics. Year is 1993. Variables are values for the candidates running in the legislative election. The observations are at the candidate level. 
Table 5: The effect of campaign spending on votes: IV estimates - French legislative elections

(a) Candidate-level analysis

\begin{tabular}{|c|c|c|c|c|c|c|c|c|}
\hline & \multicolumn{4}{|c|}{ Change in spending share } & \multicolumn{4}{|c|}{ Change in vote share } \\
\hline & $(1)$ & $(2)$ & (3) & (4) & $(5)$ & (6) & (7) & $(8)$ \\
\hline Donations from legal entities & $\begin{array}{c}-6.9^{* * *} \\
(1.1)\end{array}$ & $\begin{array}{c}-6.1^{* * *} \\
(1.1)\end{array}$ & $\begin{array}{c}-6.5^{* * *} \\
(1.4)\end{array}$ & $\begin{array}{c}-6.5^{* * *} \\
(1.4)\end{array}$ & & & & \\
\hline Change in spending share & & & & & $\begin{array}{c}0.009^{* *} \\
(0.004)\end{array}$ & $\begin{array}{l}0.008^{*} \\
(0.004)\end{array}$ & $\begin{array}{l}0.005^{*} \\
(0.003)\end{array}$ & $\begin{array}{l}0.005^{*} \\
(0.003)\end{array}$ \\
\hline District FE & & & & & $\checkmark$ & $\checkmark$ & $\checkmark$ & $\checkmark$ \\
\hline Party FE & & & & & $\checkmark$ & $\checkmark$ & $\checkmark$ & $\checkmark$ \\
\hline Candidate-level controls & & & & & & $\checkmark$ & $\checkmark$ & $\checkmark$ \\
\hline Party present in 1988 & & & & & & & $\checkmark$ & $\checkmark$ \\
\hline Party district score in 1988 & & & & & & & & $\checkmark$ \\
\hline Observations & 1,517 & 1,517 & 1,120 & 1,120 & 1,517 & 1,517 & 1,120 & 1,120 \\
\hline F-stat for Weak identification & & & & & 40 & 32 & 22 & 21 \\
\hline Underidentification ( $\mathrm{p}$-value) & & & & & 0.00 & 0.00 & 0.00 & 0.00 \\
\hline Mean DepVar & & & & & 0.01 & 0.01 & 0.05 & 0.05 \\
\hline Sd DepVar & & & & & 0.5 & 0.5 & 0.4 & 0.4 \\
\hline
\end{tabular}

(b) Party-level analysis

\begin{tabular}{|c|c|c|c|c|c|c|c|c|}
\hline & \multicolumn{4}{|c|}{ Change in spending share } & \multicolumn{4}{|c|}{ Change in vote share } \\
\hline & (1) & (2) & (3) & (4) & $(5)$ & (6) & (7) & (8) \\
\hline Donations from legal entities & $\begin{array}{c}-7.2^{* * *} \\
(1.1)\end{array}$ & $\begin{array}{c}-7.0^{* * *} \\
(1.1)\end{array}$ & $\begin{array}{c}-7.1^{* * *} \\
(1.1)\end{array}$ & $\begin{array}{c}-7.1^{* * *} \\
(1.1)\end{array}$ & & & & \\
\hline Change in spending share & & & & & $\begin{array}{c}0.011^{* * *} \\
(0.003)\end{array}$ & $\begin{array}{c}0.011^{* * *} \\
(0.003)\end{array}$ & $\begin{array}{c}0.007^{* *} \\
(0.003)\end{array}$ & $\begin{array}{l}0.006^{*} \\
(0.003)\end{array}$ \\
\hline District FE & & & & & $\checkmark$ & $\checkmark$ & $\checkmark$ & $\checkmark$ \\
\hline Party FE & & & & & $\checkmark$ & $\checkmark$ & $\checkmark$ & $\checkmark$ \\
\hline Candidate-level controls & & & & & & $\checkmark$ & $\checkmark$ & $\checkmark$ \\
\hline Party district vote share in 1988 & & & & & & & & $\checkmark$ \\
\hline Observations & 2,805 & 2,805 & 2,076 & 2,076 & 2,805 & 2,805 & 2,076 & 2,076 \\
\hline F-stat for Weak identification & & & & & 46 & 44 & 46 & 45 \\
\hline Underidentification (p-value) & & & & & 0.00 & 0.00 & 0.00 & 0.00 \\
\hline Mean DepVar & & & & & -0.04 & -0.04 & 0.07 & 0.07 \\
\hline Sd DepVar & & & & & 0.6 & 0.6 & 0.4 & 0.4 \\
\hline
\end{tabular}

Notes: $* \mathrm{p}<0.10, * * \mathrm{p}<0.05, * * * \mathrm{p}<0.01$. The models are estimated using 2SLS. Columns (1) to (4) report the first stage estimates (the dependent variable is the change in the share of spending) and Columns (5) to (8) the corresponding second stage estimates (the dependent variable is the change in the vote share (in log)). An observation is a candidate running both in 1993 and 1997 in upper Table 5a and, bottom Table 5b a political party-district competing in 1993 and 1997. Columns (3) and (4) focus on the sample of candidates whose party ran in the district in 1988; and in Columns (4) and (8) we control for the results of these candidates' party-district in 1988. The other candidate-level controls include her gender, indicator variables for the candidates' political mandates and incumbency status. Coefficients for the controls are not reported for the sake of space. Variables are described in more detail in the text. 
Table 6: The effect of campaign spending on votes: IV estimates, within-party estimations - French legislative elections

(a) Only right-wing candidates

\begin{tabular}{lccccc}
\hline \hline & \multicolumn{2}{c}{ Change in spending share } & & \multicolumn{2}{c}{ Change in vote share } \\
\cline { 2 - 3 } \cline { 5 - 6 } & $(1)$ & $(2)$ & & $(3)$ & $(4)$ \\
\hline Donations from legal entities & $-4.137^{* * *}$ & $-3.840^{* * *}$ & & \\
& $(1.026)$ & $(1.018)$ & & \\
Change in spending share & & & $0.014^{* *}$ & $0.015^{* *}$ \\
& & & & $(0.006)$ & $(0.006)$ \\
\hline Candidate-level controls & \multirow{2}{*}{398} & 398 & & 398 & 398 \\
Observations & & & & 16.3 & 14.2 \\
F-stat for Weak identification & & & 0.00 & 0.00 \\
Underidentification (p-value) & & & -0.20 & -0.20 \\
Mean DepVar & & & 0.3 & 0.3 \\
Sd DepVar & & & & \\
\hline \hline
\end{tabular}

(b) Only Socialist party candidates

\begin{tabular}{lccccc}
\hline \hline & \multicolumn{2}{c}{ Change in spending share } & & \multicolumn{2}{c}{ Change in vote share } \\
\cline { 2 - 3 } \cline { 5 - 6 } & $(1)$ & $(2)$ & & $(3)$ & $(4)$ \\
\hline Donations from legal entities & $-6.925^{* * *}$ & $-5.984^{* * *}$ & & \\
& $(2.043)$ & $(2.087)$ & & \\
Change in spending share & & & & $0.020^{* * *}$ & $0.021^{* *}$ \\
& & & & $(0.007)$ & $(0.008)$ \\
\hline Candidate-level controls & \multirow{2}{*}{211} & 211 & & 211 & 211 \\
Observations & & & & 11.5 & 8.2 \\
F-stat for Weak identification & & & 0.00 & 0.00 \\
Underidentification (p-value) & & & 0.35 & 0.35 \\
Mean DepVar & & & 0.3 & 0.3 \\
Sd DepVar & & & & \\
\hline \hline
\end{tabular}

Notes: $* \mathrm{p}<0.10, * * \mathrm{p}<0.05, * * * \mathrm{p}<0.01$. The models are estimated using 2 SLS. An observation is a candidate. Columns (1) and (2) report the first stage estimates (the dependent variable is the change in the share of spending) and Columns (3) and (4) the second stage estimates (the dependent variable is the change in the vote share (in log)). The upper Table 6a presents the results for the right-wing candidates. The bottom Table $6 \mathrm{~b}$ presents the results for the Socialist party candidates. The candidate-level controls include her gender, indicator variables for the candidates' political mandates and incumbency status. Coefficients for the controls are not reported for the sake of space. Variables are described in more detail in the text. 
Table 7: The effect of donations from legal entities on votes: Nearest-neighbor matching estimation French legislative elections, 1993-1997

\begin{tabular}{lccc}
\hline \hline & \multicolumn{3}{c}{ Change in vote share } \\
\cline { 2 - 4 } & $(1)$ & $(2)$ & $(3)$ \\
\hline Donations from legal entities & $-0.09^{* *}$ & $-0.12^{* * *}$ & $-0.08^{* *}$ \\
& $(0.04)$ & $(0.04)$ & $(0.04)$ \\
\hline Match on candidate characteristics & $\checkmark$ & & $\checkmark$ \\
Match on district characteristics & & $\checkmark$ & $\checkmark$ \\
Observations & 1,714 & 1,629 & 1,629 \\
\hline \hline
\end{tabular}

Notes: $* \mathrm{p}<0.10, * * \mathrm{p}<0.05, * * * \mathrm{p}<0.01$. The models are estimated using nearest-neighbor matching estimators. All specifications match on political parties (exact), classified in five different categories: Communist party, Socialist party, right-wing party, extreme-right party, and other. In columns (1) and (3), specifications also match on candidate-level characteristics including their gender, an indicator variable equal to one if the candidate is the mayor and to zero otherwise, and an indicator variable equal to one if the candidate is the incumbent and to zero otherwise. In columns (2) and (3), specifications also match on district-level characteristics including the population by age group, occupation and degree, the unemployment rate, the share of the employees who are part of the top $1 \%$ of the income distribution, the total spending at the district level, the number of candidates running, and the margin at last election between the first and second largest vote counts. Estimates are bias-adjusted. 
Table 8: The effect of campaign spending on votes: IV estimates, Placebo estimations - French legislative elections

(a) Placebo estimation: 1988-1993

\begin{tabular}{lcccc}
\hline \hline & $\Delta$ spending & & \multicolumn{2}{c}{ Change in vote shares } \\
\cline { 2 - 3 } & $(1)$ & & $(2)$ & $(3)$ \\
& & Placebo (88-93) & Treatment (93-97) \\
\hline Donations from legal entities & $-6.445^{* * *}$ & & & \\
& $(1.418)$ & & \\
Change in spending share & & & -0.002 & $0.005^{*}$ \\
& & & $(0.005)$ & $(0.003)$ \\
\hline District FE & & $\checkmark$ & $\checkmark$ \\
Party FE & & $\checkmark$ & $\checkmark$ \\
Candidate-level controls & & & $\checkmark$ \\
$\Delta$ Votes 88-93 control & 1,109 & & 1,109 & 1,109 \\
Observations & & 21 & 21 \\
F-stat for Weak identification & & 0.00 & 0.00 \\
Underidentification (p-value) & & 0.04 & 0.05 \\
Mean DepVar & & 0.5 & 0.4 \\
Sd DepVar & & &
\end{tabular}

(b) Placebo estimation: 1981-1988

\begin{tabular}{|c|c|c|c|}
\hline & \multirow{3}{*}{$\frac{\Delta \text { spending }}{(1)}$} & \multicolumn{2}{|c|}{ Change in vote shares } \\
\hline & & (2) & (3) \\
\hline & & Placebo (81-88) & Treatment (93-97) \\
\hline Donations from legal entities & $\begin{array}{c}-9.119^{* * *} \\
(2.533)\end{array}$ & & \\
\hline Change in spending share & & $\begin{array}{c}-0.009 \\
(0.008)\end{array}$ & $\begin{array}{l}0.005^{*} \\
(0.003)\end{array}$ \\
\hline District FE & & $\checkmark$ & $\checkmark$ \\
\hline Party FE & & $\checkmark$ & $\checkmark$ \\
\hline Candidate-level controls & & $\checkmark$ & $\checkmark$ \\
\hline$\Delta$ Votes $81-88$ control & & & \\
\hline Observations & 605 & 605 & 605 \\
\hline F-stat for Weak identification & & 13 & 13 \\
\hline Underidentification (p-value) & & 0.00 & 0.00 \\
\hline Mean DepVar & & -0.16 & 0.06 \\
\hline Sd DepVar & & 1.1 & 0.4 \\
\hline
\end{tabular}

Notes: $* \mathrm{p}<0.10, * * \mathrm{p}<0.05, * * * \mathrm{p}<0.01$. The models are estimated using 2 SLS estimates. An observation is a candidate running both in the 1993 and 1997 elections whose party also presented a candidate at the 1988 elections (upper Table 8a, respectively at the 1981 elections (bottom Table 8b. Column (1) reports the first stage estimates (the dependent variable is the change in the share of spending between 1993 and 1997), and Columns (2) and (3) the second stage estimates for different dependent variables. The dependent variable is the change in votes of the candidate's party in the district between 1988-1993 in Column (2) of upper Table 8a and between 1981 and 1988 in Column (2) of bottom Table [8b The candidate-level controls include her gender, indicator variables tor the candidates' political mandates and incumbency status. Coefficients for the controls are not reported for the sake of space. Variables are described in more detail in the text. 


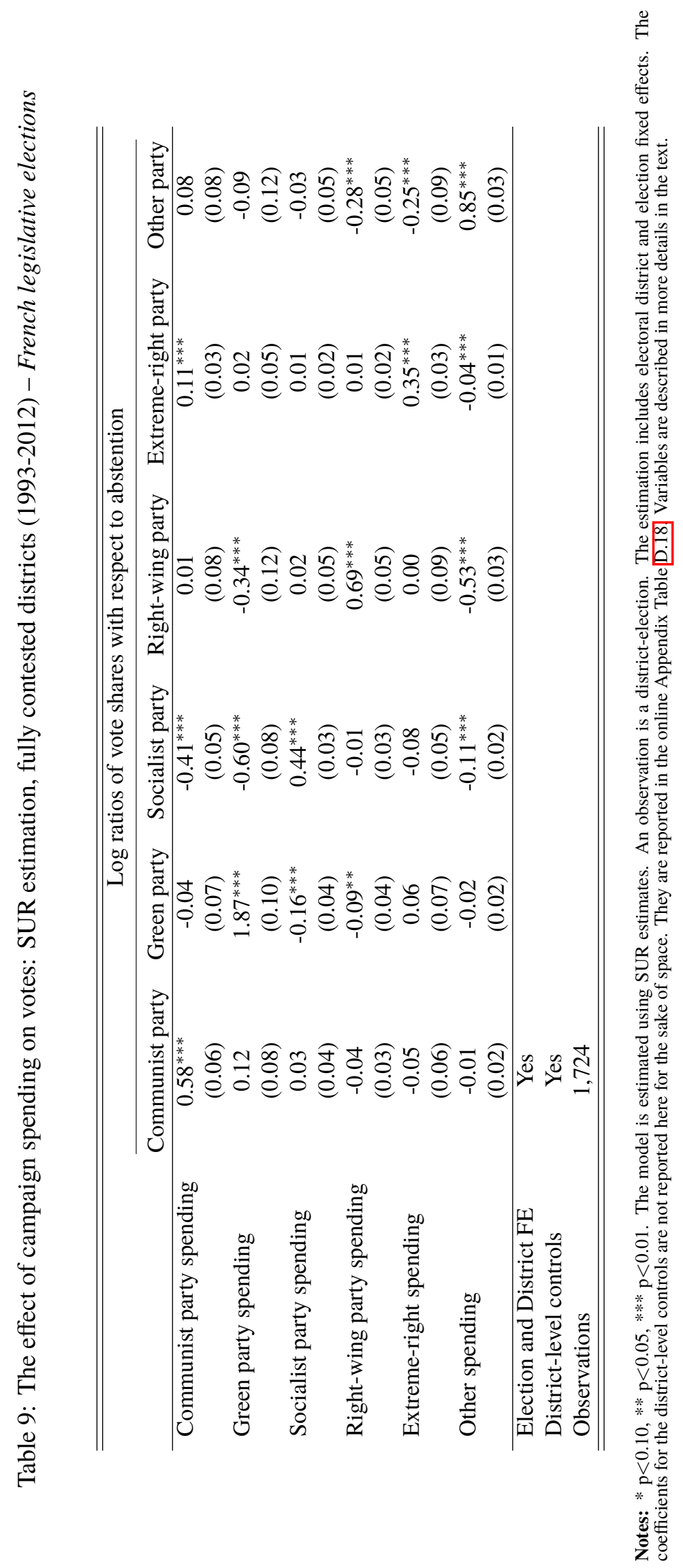


Table 10: The effect of campaign spending on votes: SUR estimation, fully contested districts - UK general elections

\begin{tabular}{lccccc}
\hline \hline & \multicolumn{6}{c}{ Log ratios of vote shares with respect to abstention } \\
\cline { 2 - 6 } & $\begin{array}{c}\text { Labour } \\
\mathrm{b} / \mathrm{se}\end{array}$ & $\begin{array}{c}\text { Liberal } \\
\mathrm{b} / \mathrm{se}\end{array}$ & $\begin{array}{c}\text { Conservative } \\
\mathrm{b} / \mathrm{se}\end{array}$ & $\begin{array}{c}\text { UKIP } \\
\mathrm{b} / \mathrm{se}\end{array}$ & $\begin{array}{c}\text { Other } \\
\mathrm{b} / \mathrm{se}\end{array}$ \\
\hline Labour spending & $0.85^{* * *}$ & $-0.71^{* * *}$ & $0.35^{* * *}$ & $-0.35^{* *}$ & -0.32 \\
& $(0.11)$ & $(0.16)$ & $(0.09)$ & $(0.17)$ & $(0.35)$ \\
Liberal spending & $-0.48^{* * *}$ & $3.32^{* * *}$ & $-0.43^{* * *}$ & -0.23 & $-0.77^{* *}$ \\
& $(0.12)$ & $(0.18)$ & $(0.10)$ & $(0.19)$ & $(0.39)$ \\
Conservative spending & $-0.24^{* *}$ & $-0.96^{* * *}$ & $0.96^{* * *}$ & $-0.34^{*}$ & -0.06 \\
& $(0.11)$ & $(0.17)$ & $(0.10)$ & $(0.18)$ & $(0.36)$ \\
UKIP spending & $-0.33^{* * *}$ & -0.26 & -0.05 & $2.25^{* * *}$ & $-0.65^{*}$ \\
& $(0.12)$ & $(0.18)$ & $(0.10)$ & $(0.19)$ & $(0.38)$ \\
Other spending & $-0.18^{*}$ & -0.14 & $-0.23^{* * *}$ & $-0.79^{* * *}$ & $4.63^{* * *}$ \\
& $(0.10)$ & $(0.15)$ & $(0.08)$ & $(0.15)$ & $(0.31)$ \\
\hline Election and District FE & Yes & & & & \\
District-level controls & Yes & & & & \\
Observations & 1,888 & & & & \\
\hline \hline
\end{tabular}

Notes: $* \mathrm{p}<0.10, * * \mathrm{p}<0.05, * * * \mathrm{p}<0.01$. The model is estimated using SUR estimates. An observation is a district-election. The estimation includes electoral district and election fixed effects. Variables are described in more details in the text. 
Table 11: The impact of campaign spending on turnout

\begin{tabular}{|c|c|c|c|c|}
\hline & \multicolumn{2}{|c|}{ France } & \multicolumn{2}{|c|}{ UK } \\
\hline & (1) & (2) & (3) & (4) \\
\hline Total spending in district & $\begin{array}{c}0.045^{* * *} \\
(0.014)\end{array}$ & & $\begin{array}{c}0.074^{* * *} \\
(0.019)\end{array}$ & \\
\hline Communist party spending & & $\begin{array}{c}0.004 \\
(0.017)\end{array}$ & & \\
\hline Green party spending & & $\begin{array}{c}0.040^{* * *} \\
(0.015)\end{array}$ & & \\
\hline Socialist party spending & & $\begin{array}{c}0.061^{* * *} \\
(0.013)\end{array}$ & & \\
\hline Right-wing party spending & & $\begin{array}{c}0.035^{* *} \\
(0.015)\end{array}$ & & \\
\hline Extreme-right spending & & $\begin{array}{c}-0.029^{* * *} \\
(0.011)\end{array}$ & & \\
\hline Labour spending & & & & $\begin{array}{c}0.063^{* * *} \\
(0.012)\end{array}$ \\
\hline Liberal spending & & & & $\begin{array}{l}0.046^{* *} \\
(0.020)\end{array}$ \\
\hline Conservative spending & & & & $\begin{array}{l}0.029^{*} \\
(0.015)\end{array}$ \\
\hline UKIP spending & & & & $\begin{array}{c}0.002 \\
(0.009) \\
\end{array}$ \\
\hline Election FE & $\checkmark$ & $\checkmark$ & $\checkmark$ & $\checkmark$ \\
\hline District FE & $\checkmark$ & $\checkmark$ & $\checkmark$ & $\checkmark$ \\
\hline District-level controls & $\checkmark$ & $\checkmark$ & $\checkmark$ & $\checkmark$ \\
\hline R-sq (within) & 0.06 & 0.10 & 0.18 & 0.19 \\
\hline Observations & 1,930 & 1,930 & 1,891 & 1,891 \\
\hline Clusters (districts) & 511 & 511 & 530 & 530 \\
\hline
\end{tabular}

Notes: $* \mathrm{p}<0.10, * * \mathrm{p}<0.05, * * * \mathrm{p}<0.01$. The models are estimated using OLS. An observation is an electoral district-year. Variables are standardized (demeaned and divided by their standard deviation) for estimates' comparison. All the estimations include electoral district fixed effects, election fixed effects and district-level controls. Coefficients for the controls are not reported for the sake of space. Standard errors are clustered at the district level. Variables are described in more detail in the text. 
Table 12: The effect of campaign spending on deterring challengers: the 1995 ban on donations from legal entities, IV estimation - French 1993-1997 legislative elections

(a) Change in the number of candidates

\begin{tabular}{|c|c|c|c|c|c|c|}
\hline & \multicolumn{3}{|c|}{ Incumbent spending } & \multicolumn{3}{|c|}{ Number of candidates } \\
\hline & $(1)$ & (2) & (3) & (4) & $(5)$ & $(6)$ \\
\hline Donations from legal entities & $\begin{array}{c}-0.201^{* * *} \\
(0.031)\end{array}$ & $\begin{array}{c}-0.224^{* * *} \\
(0.034)\end{array}$ & $\begin{array}{c}-0.228^{* * *} \\
(0.034)\end{array}$ & & & \\
\hline Incumbent spending & & & & $\begin{array}{l}-0.818 \\
(1.820)\end{array}$ & $\begin{array}{c}2.411^{* * *} \\
(0.840)\end{array}$ & $\begin{array}{c}2.428^{* * *} \\
(0.828)\end{array}$ \\
\hline District-level controls & & & & & $\checkmark$ & $\checkmark$ \\
\hline Incumbent political party & & & & & & $\checkmark$ \\
\hline Observations & 364 & 351 & 351 & 364 & 351 & 351 \\
\hline F-stat for Weak ident. & & & & 42 & 43 & 44 \\
\hline Underident. (p-value) & & & & 0.00 & 0.00 & 0.00 \\
\hline Mean DepVar & & & & 1.83 & 1.69 & 1.69 \\
\hline Sd DepVar & & & & 2.69 & 2.44 & 2.44 \\
\hline
\end{tabular}

(b) Change in challengers' spending

\begin{tabular}{|c|c|c|c|c|c|c|}
\hline & \multicolumn{3}{|c|}{ Incumbent spending } & \multicolumn{3}{|c|}{ Challengers spending } \\
\hline & (1) & (2) & (3) & (4) & (5) & (6) \\
\hline Donations from legal entities & $\begin{array}{c}-0.179^{* * *} \\
(0.037)\end{array}$ & $\begin{array}{c}-0.226^{* * *} \\
(0.041)\end{array}$ & $\begin{array}{c}-0.225^{* * *} \\
(0.041)\end{array}$ & & & \\
\hline Incumbent spending & & & & $\begin{array}{l}0.195^{*} \\
(0.103)\end{array}$ & $\begin{array}{c}0.204^{* *} \\
(0.093)\end{array}$ & $\begin{array}{c}0.201^{* *} \\
(0.090)\end{array}$ \\
\hline District-level controls & & & & & $\checkmark$ & $\checkmark$ \\
\hline Candidate-level controls & & & & & & $\checkmark$ \\
\hline Observations & 704 & 682 & 682 & 704 & 682 & 682 \\
\hline Cluster (district) & 327 & 316 & 316 & 327 & 316 & 316 \\
\hline F-stat for Weak ident. & & & & 24 & 31 & 31 \\
\hline Underident. (p-value) & & & & 0.00 & 0.00 & 0.00 \\
\hline Mean DepVar & & & & 0.06 & 0.05 & 0.05 \\
\hline Sd DepVar & & & & 0.27 & 0.27 & 0.27 \\
\hline
\end{tabular}

Notes: $* \mathrm{p}<0.10,{ }^{*} * \mathrm{p}<0.05, * * * \mathrm{p}<0.01$. The models are estimated using OLS estimates. An observation is a candidate-election. All the estimations include district fixed effects, election fixed effects, and party interacted with election fixed effects. The model in Column (4) also includes candidate fixed effects. Standard errors are clustered at the district level. The district-level controls include the share of the population by age group, occupation and degree, the investment spending in infrastructure, the number of firms, the number of employees, the total payroll, and the share of the employees who are part of the top $1 \%$ of the income distribution. The candidate-level controls include indicator variables for the candidates' political mandates, an indicator variable equal to one if the candidate is the incumbent and to zero otherwise, their political party, and their political party interacted with time. Coefficients for the controls are not reported for the sake of space. The upper Table 12a estimates the effect of the total spending per elector of the candidate on the log of the ratio of the votes obtained by the candidate over the abstention for the legislative elections. The bottom Table $12 \mathrm{~b}$ estimates the same model for the municipal elections. Variables are described in more detail in the text. 